\title{
A Two-Acceptor Cyanine-Based Fluorescent Indicator for NAD(P)H in Tumor Cell Models
}

\section{Supporting Information}

Maksim A. Fomin, ${ }^{1,2, \dagger}$ Ruslan I. Dmitriev, ${ }^{3, \dagger}$ James Jenkins, ${ }^{3}$ Dmitri B. Papkovsky, ${ }^{3}$ Dieter Heindl ${ }^{1}$ and Burkhard König. ${ }^{2, *}$

${ }^{1}$ Roche Diagnostics GmbH, Nonnenwald 2, D-82377 Penzberg, Germany

${ }^{2}$ Institut für Organische Chemie, Universität Regensburg, D-93040 Regensburg, Germany

${ }^{3}$ School of Biochemistry and Cell Biology, University College Cork, Cork, Ireland

Contact Information:

Burkhard König

*burkhard.koenig@chemie.uni-regensburg.de

Table of Contents:

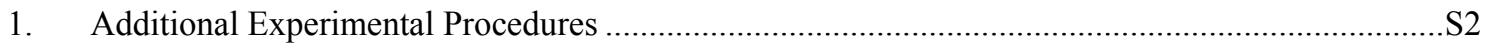

2. Synthesis and Structure Confirmation of the Cyanine Chromophore ………...................................S8

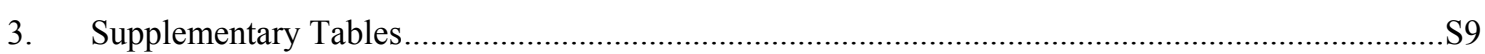

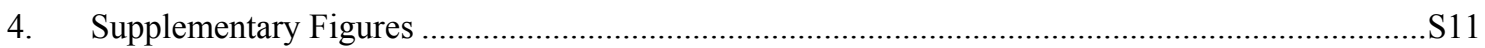

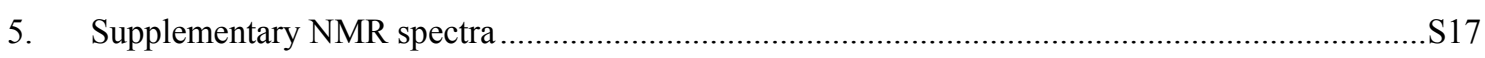

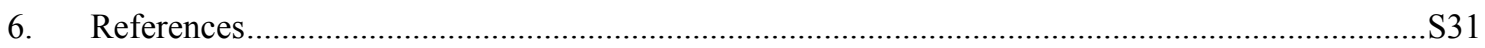




\section{Additional Experimental Procedures}

\section{SYNTHESIS MATERIALS AND METHODS}

Reagents and solvents were purchased at the highest commercial quality from Sigma-Aldrich and used without further purification. CHROMASOLV solvents were used as eluents in HPLC. 5-quinolinecarboxaldehyde (10), 6quinolinecarboxaldehyde (11) and 3-isoquinolinecarboxaldehyde (13) were from ABCR GmbH (Germany); 3pyridinecarboxaldehyde (12) was from Sigma-Aldrich (Germany); 1-phenazine-carboxaldehyde (14) was from Princeton Building Blocks (US). Yields refer to chromatographically (HPLC-MS) and spectroscopically $\left({ }^{1} \mathrm{H}\right.$ NMR) homogeneous material, unless otherwise stated. Counter anions are omitted for clarity.

TLC. Reactions were monitored by thin layer chromatography (TLC) carried out on Merck silica plates 60 F254 and 60 RP-18 F254s, using shortwave UV light as the visualizing agent and a solution of $\mathrm{KMnO}_{4}$ and heat as developing agent. Some TLC plates were pre-treated with $\mathrm{MeOH}$ solution of $\mathrm{KBr}$ (saturated) as described in literature. ${ }^{1}$ In each case they are noted as $\mathrm{SiO}_{2} \mathrm{KBr}$.

Analytical HPLC-MS (ESI-MS). The purity of the compounds was determined with the help of an HPLC-MS apparatus from Waters (Milford, USA) containing the following components: 2695 Separation module, 2696 photodiode array and Waters Micromass ZQ (ESCI ionization mode) detectors. Data acquisition was carried out by MassLynx (V4.1) software.

Column: YMC-Triart C18 $3 \mu \mathrm{M}(4.6$ x $150 \mathrm{~mm})$ /Product Nr.TA12S03-1546WT.

Flow: $0.7 \mathrm{~mL} / \mathrm{min}$.

Phase A: triethylammonium acetate (TEAAc) buffer (10 mM, pH 7.0) in deionized water.

Phase B: MeCN.

Gradient 80: 5-80B (7 min); 80-80B (2 min); 80-5B (0.5 min); 5-5B (2.5 min).

Gradient 100: 5-100B (7 min); 100-100B (2 min); 100-5B (0.5 min); 5-5B (2.5 min).

NMR. NMR spectra were recorded on a Bruker Avance (500 and $600 \mathrm{MHz}$ ) and an Agilent $400 \mathrm{MR}$ DD2 (400 MHz) instruments and were calibrated using residual non-deuterated solvent as an internal reference. ${ }^{2}$ The following abbreviations were used to explain NMR peak multiplicities: $\mathrm{s}=$ singlet, $\mathrm{d}=$ doublet, $\mathrm{t}=$ triplet, $\mathrm{q}=$ quartet, $\mathrm{m}=$ multiplet, $\mathrm{br}=$ broad.

HRMS. For HRMS (high resolution mass spectra), samples were dissolved in $\mathrm{MeCN}$ and analyzed by direct-flow injection (injection volume $=5 \mu \mathrm{L}$ ) electrospray ionization time-of-flight (ESI-TOF) mass spectrometry on a Waters Q-ToF Premier instrument in the positive ion mode.

General procedure I. Preparation of indolium salts (15-19). A mixture of a respective aldehyde (1 equiv.) and indolium iodide 8 ( 1 equiv.) in ethanol was refluxed for $2-16 \mathrm{~h}$ in the presence of piperidine (0.1-0.4 equiv.) under Ar. The reaction mixture was allowed to cool slowly to rt, and a deposited precipitate was filtered and washed with cold ethanol and ether, dried in vacuo.

General procedure II. Preparation of diquaternary salts (2-6). TfOMe (4-20 equiv.) was added to a respective indolium salt (1 equiv.) in dry DCM at rt under Ar. After the mixture was stirred for $16 \mathrm{~h}$, a deposited precipitate was filtered and washed with DCM and ether, dried in vacuo. 


\section{SPECTROSCOPIC MATERIALS AND METHODS}

All aqueous solutions were made up in deionized water with resistivity $\geq 18 \mathrm{M} \mathrm{cm}^{-1}$, obtained using a Millipore purification system (MQ-water). ${ }^{3}$ For NADH-response screening, phosphate buffer $(50 \mathrm{mM}, \mathrm{pH} 7.0)$ was prepared by mixing equimolar stock solutions of $\mathrm{K}_{2} \mathrm{HPO}_{4}$ and $\mathrm{KH}_{2} \mathrm{PO}_{4}$. Piperazine- $N$, $N^{\prime}$-bis(2-ethanesulfonic acid) (PIPES) and sodium chloride were used to make buffered solutions ( $25 \mathrm{mM}$ PIPES, $101 \mathrm{mM} \mathrm{NaCl}, \mathrm{pH}$ 7.0). $\beta$-Nicotinamide adenine dinucleotide, reduced disodium salt hydrate (NADH, Grade I) was from Roche (Germany). Stock solutions of 1-6 were prepared in MQ-water with the help of ultrasonic. Stock solutions of NADH were prepared in buffer freshly before the measurements.

UV-Vis and fluorescence. Fluorescence spectra were recorded on a Cary Eclipse fluorescence spectrophotometer and absorption spectra on a Cary $50 \mathrm{UV}$-Vis spectrometer from Varian. All measurements were performed in 1-cm UV-Vis disposable cuvettes (BRAND semi-micro) and air-equilibrated solutions at $25 \pm 0.1^{\circ} \mathrm{C}$. Emission and UV-Vis scan spectra were recorded using following parameters: average time $0.1 \mathrm{~s}$; data interval $1 \mathrm{~nm}$; scan rate $600 \mathrm{~nm} / \mathrm{min}$; with base line correction.

Extinction coefficients. Stock solutions of compounds 1-6 were diluted to 1.0-mM. For a measurement, $1000 \mu \mathrm{L}$ of the buffer and 1-20 $\mu \mathrm{L}$ of 1-6 (1.0 mM) were mixed in a cuvette. Absorbance spectra (240-900 nm) were measured against a blank of the buffer. At least six concentrations of each compound were used to calculate extinction coefficients presented in Table S1.

UV-Vis screening of diquaternary salts (1-6) with NADH. An assay solution of 1-6 (0.2-2.0 mM) in buffer (1000 $\mu \mathrm{L})$ and $2-50 \mu \mathrm{l}$ of NADH $(10.0 \mathrm{mM})$ were mixed in a cuvette. Absorbance spectra $(400-900 \mathrm{~nm})$ were recorded for 30 min every $0.2 \mathrm{~min}$ (Table S1).

Fluorescence assay of NADH with indicator 1. A stock solution of $1(10.0 \mathrm{mM})$ was diluted to $1.0 \mathrm{mM}$. A stock solution of NADH $(10.0 \mathrm{mM})$ was diluted to $50-500 \mu \mathrm{M}$ aliquots. To a $1000-\mu \mathrm{L}$ assay solution of $\mathbf{1}(20.0 \mu \mathrm{M})$ in PIPES buffer, $10 \mu \mathrm{L}$ aliquots of NADH were added to yield final concentrations of $0.5-5.0 \mu \mathrm{M}$. The resulting solutions were mixed well and then incubated for $30 \mathrm{~min}$ in a thermostat, before fluorescence emission (545-800 $\mathrm{nm}$ ) was measured $\left(\lambda_{\mathrm{ex}}=537 \mathrm{~nm}\right.$, slit widths: $5 / 5 \mathrm{~nm}$ ). Blank solutions were prepared in the same manner without NADH addition.

\section{LIVE CELL IMAGING}

Staining of HEK-293 cells with compound 1. HEK-293 cells were cultured in DMEM (Dulbecco Modified Eagle Medium) in an atmosphere of $5 \% \mathrm{CO}_{2}$ and $20 \% \mathrm{O}_{2}$ at $37^{\circ} \mathrm{C}$. Staining with $1(20 \mu \mathrm{M})$ ranged between $0.5-24 \mathrm{~h}$. As a control group, HEK-293 cells were pre-treated with 4\% paraformaldehyde (Invitrogen GAS001 Fix \& Perm Medium A). Before analysis, cells were washed with PBS buffer three times. Fluorescence images were acquired using a confocal laser scanning microscope Digital Eclipse TE 2000-E (Nikon GmbH Düsseldorf, Germany) with Nikon D-Eclipse C1si spectral detector and Nikon D-Eclipse C1 LSM, 4 laser system; and were analyzed using the confocal microscope Digital Eclipse $\mathrm{C} 1$ control software EZ-C1 (version 3.80). The excitation wavelength for imaging with NAD(P)H-indicator 1 were 488 and $561 \mathrm{~nm}$, and emission was selected and recorded using a 580 to $610 \mathrm{~nm}$ band-pass filter. 


\section{SYNTHESIS OF DIQUATERNARY SALTS}

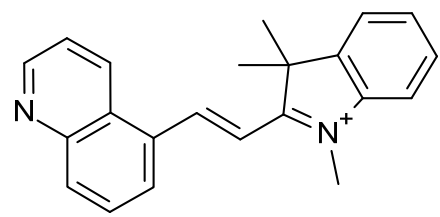

Compound 15 (450 mg, $1.02 \mathrm{mmol}$ ) was obtained following the general procedure I, from aldehyde 10 (200 $\mathrm{mg}$, $1.27 \mathrm{mmol})$, indolium-iodide $8(382 \mathrm{mg}, 1.27 \mathrm{mmol})$ and piperidine $(13 \mu \mathrm{L}, 13 \mathrm{mmol})$ in ethanol $(10 \mathrm{~mL})$ refluxed for 3 h under Ar. MF: $\mathrm{C}_{22} \mathrm{H}_{21} \mathrm{~N}_{2}$-I. FW: 440.32 . Yield: $80 \%$. Physical State: orange powder. ${ }^{1} \mathrm{H}$ NMR (DMSO- $d_{6}, 400 \mathrm{MHz}$ ): $\delta(\mathrm{ppm}) 9.06(\mathrm{dd}, J=4.0,1.5 \mathrm{~Hz}, 1 \mathrm{H}), 8.98(\mathrm{~d}, J=16.4 \mathrm{~Hz}, 1 \mathrm{H}), 8.89$ (dd, $J=8.6,1.5 \mathrm{~Hz}, 1 \mathrm{H}), 8.56(\mathrm{~d}, J=7.3 \mathrm{~Hz}, 1$ H), $8.30(\mathrm{~d}, J=8.3 \mathrm{~Hz}, 1 \mathrm{H}), 7.96-8.03(\mathrm{~m}, 1 \mathrm{H}), 8.00(\mathrm{dd}, J=8.3,7.3 \mathrm{~Hz}, 1 \mathrm{H}), 7.92-7.96(\mathrm{~m}, 1 \mathrm{H}), 7.84(\mathrm{~d}, J=16.4$ $\mathrm{Hz}, 1 \mathrm{H}), 7.76(\mathrm{dd}, J=8.6,4.0 \mathrm{~Hz}, 1 \mathrm{H}), 7.68(\mathrm{dd}, J=5.8,3.0 \mathrm{~Hz}, 2 \mathrm{H}), 4.24(\mathrm{~s}, 3 \mathrm{H}), 1.88(\mathrm{~s}, 6 \mathrm{H}) .{ }^{13} \mathbf{C}$ NMR (DMSO- $\left.d_{6}, 101 \mathrm{MHz}\right): \delta$ (ppm) 182.0, 151.4, 147.7, 147.1, 143.7, 141.9, 133.9, 132.4, 132.0, 129.9, 129.4, 129.2, 127.7, 126.5, 123.1, 122.7, 116.6, 115.7, 52.6, 35.1, 25.2 (2C). HRMS: $\mathrm{m} / \mathrm{z} 313.1710\left([\mathrm{M}-\mathrm{I}]^{+}\right)$calculated for $\mathrm{C}_{22} \mathrm{H}_{21} \mathrm{~N}_{2}{ }^{+}$: 313.1705 ( $\triangle 1.6$ ppm). $\mathbf{R}_{\mathbf{f}}: 0.4\left(\mathrm{NP} \mathrm{SiO}_{2} \mathrm{KBr} ; \mathrm{DCM} / \mathrm{MeOH} 9: 1\right)$.

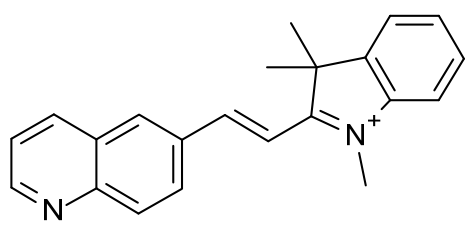

Compound 16 (436 mg, $0.99 \mathrm{mmol}$ ) was obtained following the general procedure I, from aldehyde 11 (200 mg, $1.23 \mathrm{mmol})$, indolium-iodide $8(381 \mathrm{mg}, 1.24 \mathrm{mmol})$ and piperidine $(12 \mu \mathrm{L}, 0.12 \mathrm{mmol})$ in ethanol $(10 \mathrm{~mL})$ refluxed for $16 \mathrm{~h}$ under Ar. MF: $\mathrm{C}_{22} \mathrm{H}_{21} \mathrm{~N}_{2}$-I. FW: 440.32. Yield: $80 \%$. Physical State: orange powder. ${ }^{1} \mathbf{H}$ NMR (DMSO-d ${ }_{6}$, 600MHz): $\delta(\mathrm{ppm}) 9.04(\mathrm{dd}, J=4.1,1.7 \mathrm{~Hz}, 1 \mathrm{H}), 8.83(\mathrm{~d}, J=1.8 \mathrm{~Hz}, 1 \mathrm{H}), 8.63(\mathrm{dd}, J=8.9,1.8 \mathrm{~Hz}, 1 \mathrm{H}), 8.62(\mathrm{~d}$, $J=16.4 \mathrm{~Hz}, 1 \mathrm{H}), 8.48(\mathrm{dd}, J=8.3,1.7 \mathrm{~Hz}, 1 \mathrm{H}), 8.17$ (d, $J=8.9 \mathrm{~Hz}, 1 \mathrm{H}), 7.94-7.97$ (m, $1 \mathrm{H}), 7.90-7.93$ (m, $1 \mathrm{H})$, $7.87(\mathrm{~d}, J=16.4 \mathrm{~Hz}, 1 \mathrm{H}), 7.68(\mathrm{dd}, J=8.3,4.1 \mathrm{~Hz}, 1 \mathrm{H}), 7.64-7.70(\mathrm{~m}, 2 \mathrm{H}), 4.23(\mathrm{~s}, 3 \mathrm{H}), 1.85(\mathrm{~s}, 6 \mathrm{H}) .{ }^{13} \mathbf{C} \mathbf{N M R}$ (DMSO-d ${ }_{6}, 151 \mathrm{MHz}$ ): $\delta$ (ppm) 181.7, 152.8, 149.3, 143.6, 141.7, 137.1, 133.6, 132.5, 129.8, 129.5, 128.9, 127.9, 127.7, 122.8, 122.6, 115.3, 114.3, 52.3, 34.7, 25.1 (2C). HRMS: $m / z 313.1699\left([\mathrm{M}-\mathrm{I}]^{+}\right)$calculated for $\mathrm{C}_{22} \mathrm{H}_{21} \mathrm{~N}_{2}{ }^{+}: 313.1705$ (4 1.9 ppm). $\mathbf{R}_{\mathbf{f}}: 0.3$ (NP $\left.\mathrm{SiO}_{2} \mathrm{KBr} ; \mathrm{DCM} / \mathrm{MeOH} 9: 1\right)$.

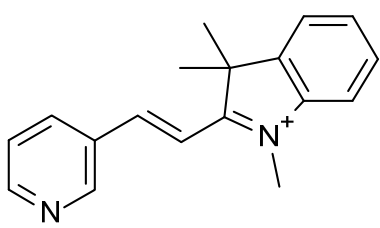

Compound $17(637 \mathrm{mg}, 1.63 \mathrm{mmol})$ was obtained following the general procedure I, from aldehyde $\mathbf{1 2}(200 \mu \mathrm{L}$, $2.13 \mathrm{mmol})$, indolium-iodide $8(641 \mathrm{mg}, 2.13 \mathrm{mmol})$ and piperidine $(21 \mu \mathrm{L}, 0.21 \mathrm{mmol})$ in ethanol $(20 \mathrm{~mL})$ refluxed for $8 \mathrm{~h}$ under Ar. MF: $\mathrm{C}_{18} \mathrm{H}_{19} \mathrm{~N}_{2}$-I. FW: 390.26. Yield: 77\%. Physical State: orange needles. ${ }^{1} \mathrm{H}$ NMR (DMSO-d $\mathrm{d}_{6}$, 400MHz): $\delta(\mathrm{ppm}) 9.30(\mathrm{~d}, J=1.8 \mathrm{~Hz}, 1 \mathrm{H}), 8.75(\mathrm{dd}, J=4.8,1.8 \mathrm{~Hz}, 1 \mathrm{H}), 8.65(\mathrm{dt}, J=8.1,1.8 \mathrm{~Hz}, 1 \mathrm{H}), 8.44(\mathrm{~d}$, $J=16.7 \mathrm{~Hz}, 1 \mathrm{H}), 7.92-7.98(\mathrm{~m}, J=6.1,3.0 \mathrm{~Hz}, 1 \mathrm{H}), 7.87-7.93(\mathrm{~m}, J=5.8,2.8 \mathrm{~Hz}, 1 \mathrm{H}), 7.82(\mathrm{~d}, J=16.7 \mathrm{~Hz}, 1 \mathrm{H})$, $7.66(\mathrm{dd}, J=5.8,3.3 \mathrm{~Hz}, 2 \mathrm{H}), 7.63(\mathrm{dd}, J=8.1,4.8 \mathrm{~Hz}, 1 \mathrm{H}), 4.19$ (s, $3 \mathrm{H}), 1.81$ (s, $6 \mathrm{H}) .{ }^{13} \mathbf{C}$ NMR (DMSO-d 6 , $101 \mathrm{MHz}): \delta$ (ppm) 181.8, 152.9, 151.6, 149.3, 143.8, 141.8, 136.1, 130.3, 129.8, 129.1, 124.2, 122.9, 115.6, 115.0, 52.5, 
34.9, 25.0 (2C). HRMS: $m / z 263.1561\left([\mathrm{M}-\mathrm{I}]^{+}\right)$calculated for $\mathrm{C}_{18} \mathrm{H}_{19} \mathrm{~N}_{2}^{+}: 263.1548(\Delta 4.9 \mathrm{ppm}) . \mathbf{R}_{\mathbf{f}}: 0.7\left(\mathrm{RP}-18 \mathrm{SiO}_{2}\right.$; $\left.\mathrm{MeCN} / \mathrm{H}_{2} \mathrm{O} / \mathrm{TFA}-80: 20: 0.1\right)$.

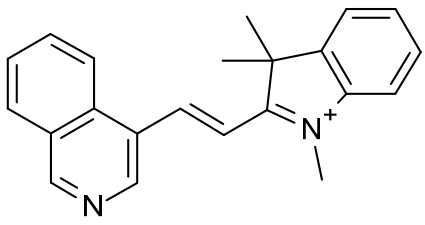

Compound $18(438 \mathrm{mg}, 1.00 \mathrm{mmol})$ was obtained following the general procedure I, from aldehyde 13 (200 $\mathrm{mg}$, $1.27 \mathrm{mmol})$, indolium-iodide 8 (382 $\mathrm{mg}, 1.27 \mathrm{mmol})$ and piperidine $(13 \mu \mathrm{L}, 0.13 \mathrm{mmol})$ in ethanol $(10 \mathrm{~mL})$ refluxed for $3 \mathrm{~h}$ under Ar. MF: $\mathrm{C}_{22} \mathrm{H}_{21} \mathrm{~N}_{2}$-I. FW: 440.32. Yield: 79\%. Physical State: orange powder. ${ }^{1} \mathbf{H}$ NMR (DMSO-d $\mathrm{d}_{6}$, 400MHz): $\delta(\mathrm{ppm}) 9.53$ (s, $1 \mathrm{H}), 9.34(\mathrm{~s}, 1 \mathrm{H}), 8.94$ (d, $J=16.4 \mathrm{~Hz}, 1 \mathrm{H}), 8.44(\mathrm{~d}, J=8.3 \mathrm{~Hz}, 1 \mathrm{H}), 8.31$ (d, $J=8.1 \mathrm{~Hz}$, $1 \mathrm{H}), 8.03$ (ddd, $J=8.3,7.1,1.3 \mathrm{~Hz}, 1 \mathrm{H}), 7.96-8.00(\mathrm{~m}, 1 \mathrm{H}), 7.92-7.96(\mathrm{~m}, 1 \mathrm{H}), 7.90(\mathrm{~d}, J=16.4 \mathrm{~Hz}, 1 \mathrm{H}), 7.86(\mathrm{dd}$, $J=8.1,7.1 \mathrm{~Hz}, 1 \mathrm{H}), 7.64-7.73$ (m, $2 \mathrm{H}), 4.25$ (s, $3 \mathrm{H}), 1.88$ (s, $6 \mathrm{H}) .{ }^{13} \mathbf{C}$ NMR (DMSO-d 6 , 101 MHz): $\delta$ (ppm) 182.0, 156.0, 146.3, 143.7, 143.5, 141.9, 132.9, 132.4, 129.9, 129.1, 128.8, 128.5, 127.7, 125.5, 123.0, 122.9, 116.9, 115.7, 52.7, 35.1, 25.2 (2C). HRMS: $m / z 313.1706\left([\mathrm{M}-\mathrm{I}]^{+}\right)$calculated for $\mathrm{C}_{22} \mathrm{H}_{21} \mathrm{~N}_{2}{ }^{+}: 313.1705$ (4 $\left.0.3 \mathrm{ppm}\right)$. $\mathbf{R}_{\mathbf{f}}: 0.6(\mathrm{RP} 18$ $\mathrm{SiO}_{2} ; \mathrm{MeCN} / \mathrm{H}_{2} \mathrm{O} / \mathrm{TFA}$ 80:20:0.1).

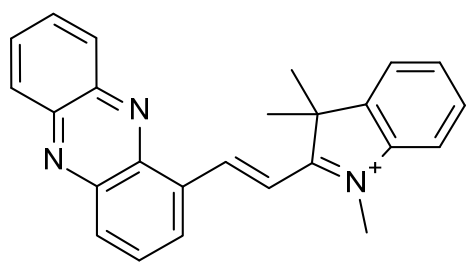

Compound 19 (810 mg, $1.65 \mathrm{mmol}$ ) was obtained following the general procedure I, from aldehyde 14 (400 $\mathrm{mg}$, $1.92 \mathrm{mmol})$, indolium-iodide 8 (578 $\mathrm{mg}, 1.92 \mathrm{mmol})$ and piperidine $(20 \mu \mathrm{L}, 0.20 \mathrm{mmol})$ in ethanol $(20 \mathrm{~mL})$ refluxed for $8 \mathrm{~h}$ under Ar. MF: $\mathrm{C}_{25} \mathrm{H}_{22} \mathrm{~N}_{3}$-I. FW: 491.38. Yield: $86 \%$. Physical State: red powder. ${ }^{1} \mathrm{H}$ NMR (DMSO-d 6 , 600MHz): $\delta$ (ppm) $9.47(\mathrm{~d}, J=16.6 \mathrm{~Hz}, 1 \mathrm{H}), 8.99$ (dd, $J=7.1,1.1 \mathrm{~Hz}, 1 \mathrm{H}), 8.54$ (dd, $J=8.7,1.1 \mathrm{~Hz}, 1 \mathrm{H}), 8.51(\mathrm{~d}, J=16.6 \mathrm{~Hz}$, $1 \mathrm{H}), 8.39-8.44(\mathrm{~m}, 1 \mathrm{H}), 8.34-8.37(\mathrm{~m}, 1 \mathrm{H}), 8.22(\mathrm{dd}, J=8.7,7.1 \mathrm{~Hz}, 1 \mathrm{H}), 8.07-8.14(\mathrm{~m}, 2 \mathrm{H}), 8.00-8.05(\mathrm{~m}, 1 \mathrm{H})$, 7.95-7.99 (m, 1H), 7.68-7.73 (m, 2H), 4.29 (s, 3H), 1.95 (s, 6H). ${ }^{13}$ C NMR (DMSO-d $\left.\mathrm{d}_{6}, 151 \mathrm{MHz}\right): \delta$ (ppm) 181.9, 146.8, $143.5,143.1,142.7,142.1,141.8,140.8,134.1,133.3,132.2,131.9,130.7,129.7,129.6,129.3,129.0,122.9,116.2$, 115.5, 52.3, 34.8, 25.6 (2C). HRMS: $m / z 364.1807\left([\mathrm{M}-\mathrm{I}]^{+}\right)$calculated for $\mathrm{C}_{25} \mathrm{H}_{22} \mathrm{~N}_{3}{ }^{+}: 364.1808\left(\Delta-0.3\right.$ ppm). $\mathbf{R}_{\mathbf{f}}: 0.3$ $\left(\mathrm{NP} \mathrm{SiO}_{2} \mathrm{KBr} ; \mathrm{DCM} / \mathrm{MeOH} 9: 1\right)$.

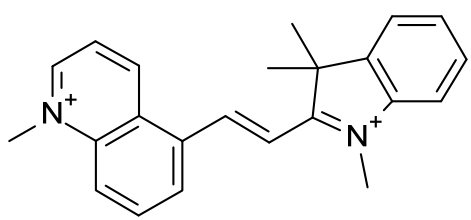

Compound 2 (243 mg, $0.40 \mathrm{mmol}$ ) was obtained following the general procedure II, from a suspension of indolium salt 15 (200 mg, $0.45 \mathrm{mmol})$ in DCM $(15 \mathrm{~mL})$ and TfOMe $(206 \mu \mathrm{L}, 1.82 \mathrm{mmol})$ under Ar. MF: $\mathrm{C}_{23} \mathrm{H}_{24} \mathrm{~N}_{2}\left(\mathrm{CF}_{3} \mathrm{O}_{3} \mathrm{~S} ; \mathrm{I}\right)$. FW: 604.43. Yield: $89 \%$. Physical State: yellow powder. ${ }^{1}$ H NMR (DMSO-d $\left.{ }_{6}, 400 \mathrm{MHz}\right): \delta$ (ppm) 9.63 (d, $J=8.8 \mathrm{~Hz}, 1 \mathrm{H}$ ), $9.60(\mathrm{~d}, J=5.6 \mathrm{~Hz}, 1 \mathrm{H}), 9.02(\mathrm{~d}, J=16.2 \mathrm{~Hz}, 1 \mathrm{H}), 8.80(\mathrm{~d}, J=7.3 \mathrm{~Hz}, 1 \mathrm{H}), 8.73(\mathrm{~d}, J=8.8 \mathrm{~Hz}, 1 \mathrm{H}), 8.45(\mathrm{dd}$, $J=8.8,7.3 \mathrm{~Hz}, 1 \mathrm{H}), 8.31(\mathrm{dd}, J=8.8,5.6 \mathrm{~Hz}, 1 \mathrm{H}), 8.00-8.07(\mathrm{~m}, 1 \mathrm{H}), 7.93-7.98(\mathrm{~m}, 1 \mathrm{H}), 7.93(\mathrm{~d}, J=16.2 \mathrm{~Hz}, 1 \mathrm{H})$, 7.67-7.75 (m, 2 H), 4.71 (s, 3 H), 4.27 (s, 3 H), 1.89 (s, 6 H). ${ }^{13}$ C NMR (DMSO-d $\left.6,101 \mathrm{MHz}\right): \delta$ (ppm) 182.3, 150.8, 
145.0, 143.9, 143.8, 141.9, 138.9, 134.7, 134.1, 130.3, 130.0, 129.3, 127.3, 123.1, 122.6, 119.4, 116.0, 52.9, 46.2, 35.4, 24.8 (2C). HRMS: $m / z 328.1933\left([\mathrm{M}-\mathrm{TfO}-\mathrm{I}]^{+}\right)$calculated for $\mathrm{C}_{23} \mathrm{H}_{24} \mathrm{~N}_{2}{ }^{+}: 328.1939(4-1.8 \mathrm{ppm})$. HPLC-MS (gradient 80) $\mathrm{m} / \mathrm{z} 327.2\left([\mathrm{M}-\mathrm{H}-\mathrm{TfO}-\mathrm{I}]^{+}\right)$; retention time $5.2 \mathrm{~min}$. $\mathbf{R}_{\mathrm{f}}: 0.5\left(\mathrm{RP}-18 \mathrm{SiO}_{2} ; \mathrm{MeCN} / \mathrm{H}_{2} \mathrm{O} / \mathrm{TFA}-80: 20: 0.1\right)$. Solubility in water: $\geq 29 \mathrm{mM}$.

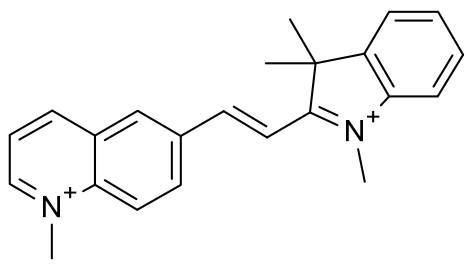

Compound 3 (272 mg, $0.45 \mathrm{mmol}$ ) was obtained following the general procedure II, from a suspension of indolium salt $16(200 \mathrm{mg}, 0.45 \mathrm{mmol})$ in DCM $(20 \mathrm{~mL})$ and TfOMe $(206 \mu \mathrm{L}, 1.82 \mathrm{mmol})$ under Ar. MF: $\mathrm{C}_{23} \mathrm{H}_{24} \mathrm{~N}_{2}\left(\mathrm{CF}_{3} \mathrm{O}_{3} \mathrm{~S} ; \mathrm{I}\right)$. FW: 604.43. Yield: $99 \%$. Physical State: yellow powder. ${ }^{1} \mathrm{H}$ NMR (DMSO-d 6 , 600MHz): $\delta$ (ppm) 9.56 (d, $J=5.7 \mathrm{~Hz}, 1 \mathrm{H}$ ), $9.26(\mathrm{~d}, J=8.4 \mathrm{~Hz}, 1 \mathrm{H}), 9.16(\mathrm{~d}, J=1.7 \mathrm{~Hz}, 1 \mathrm{H}), 9.04(\mathrm{dd}, J=9.4,1.7 \mathrm{~Hz}, 1 \mathrm{H}), 8.68(\mathrm{~d}, J=9.3 \mathrm{~Hz}, 1 \mathrm{H}), 8.64(\mathrm{~d}$, $J=16.5 \mathrm{~Hz}, 1 \mathrm{H}), 8.26(\mathrm{dd}, J=8.4,5.7 \mathrm{~Hz}, 1 \mathrm{H}), 8.01(\mathrm{~d}, J=16.5 \mathrm{~Hz}, 1 \mathrm{H}), 7.96-8.01(\mathrm{~m}, 1 \mathrm{H}), 7.92-7.96(\mathrm{~m}, 1 \mathrm{H})$, 7.67-7.73 (m, 2 H), 4.69 (s, 3 H), 4.27 (s, 3 H), 1.85 (s, 6 H). ${ }^{13}$ C NMR (DMSO-d 6 , 101MHz): $\delta$ (ppm) 181.7, 151.4, 148.8, 147.6, 144.0, 141.8, 139.7, 135.3, 133.9, 133.1, 130.1, 129.3, 129.1, 123.2, 123.0, 120.3, 116.9, 115.8, 52.6, 45.6, 35.1, 24.8 (2C). HRMS: (pos. ESI): $m / z 164.0946\left([\mathrm{M}-\mathrm{TfO}-\mathrm{I}]^{2+}\right.$ ) calculated for $\mathrm{C}_{23} \mathrm{H}_{24} \mathrm{~N}_{2}{ }^{2+}: 164.0969(4-1.4 \mathrm{ppm})$. HPLC-MS (gradient 80) $\mathrm{m} / \mathrm{z} 327.1\left([\mathrm{M}-\mathrm{H}-\mathrm{TfO}-\mathrm{I}]^{+}\right.$); retention time $5.4 \mathrm{~min}$. Solubility in water: $\geq 14 \mathrm{mM}$.

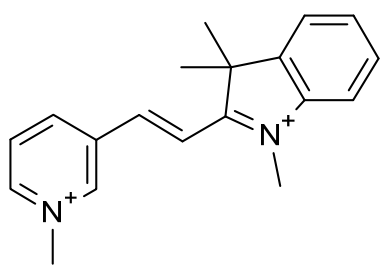

Compound 4 (272 mg, $0.49 \mathrm{mmol})$ was obtained following the general procedure II, from a solution of indolium salt 17 $(200 \mathrm{mg}, 0.51 \mathrm{mmol})$ in DCM $(25 \mathrm{~mL})$ and TfOMe $(290 \mu \mathrm{L}, 2.56 \mathrm{mmol})$ under Ar. MF: $\mathrm{C}_{19} \mathrm{H}_{22} \mathrm{~N}_{2}\left(\mathrm{CF}_{3} \mathrm{O}_{3} \mathrm{~S} ; \mathrm{I}\right)$. FW: 554.36. Yield: 96\%. Physical State: yellow powder. ${ }^{1}$ H NMR (DMSO-d $\left.{ }_{6}, 400 \mathrm{MHz}\right): \delta$ (ppm) $9.63(\mathrm{~s}, 1 \mathrm{H}), 9.26$ (d, $J=8.3 \mathrm{~Hz}, 1 \mathrm{H}), 9.09(\mathrm{~d}, J=6.1 \mathrm{~Hz}, 1 \mathrm{H}), 8.41(\mathrm{~d}, J=16.7 \mathrm{~Hz}, 1 \mathrm{H}), 8.32(\mathrm{dd}, J=8.3,6.1 \mathrm{~Hz}, 1 \mathrm{H}), 8.00-8.04(\mathrm{~m}, 1$ H), $7.97(\mathrm{~d}, J=16.7 \mathrm{~Hz}, 1 \mathrm{H}), 7.90-7.94(\mathrm{~m}, 1 \mathrm{H}), 7.67-7.75(\mathrm{~m}, 2 \mathrm{H}), 4.42(\mathrm{~s}, 3 \mathrm{H}), 4.23(\mathrm{~s}, 3 \mathrm{H}), 1.81$ (s, $6 \mathrm{H}) .{ }^{13} \mathbf{C}$ NMR (DMSO-d $\left.{ }_{6}, 101 \mathrm{MHz}\right): \delta$ (ppm) 181.3, 146.9, 146.7, 144.1, 143.7, 143.4, 141.8, 133.9, 130.5, 129.3, 127.8, 123.0, 120.7 (q, $J=322 \mathrm{~Hz}, \mathrm{TfO}), 118.6,116.1,52.8,48.4,35.4,24.5$ (2C). HRMS: $m / z 278.1795$ ([M - TfO - I] ${ }^{+}$) calculated for $\mathrm{C}_{19} \mathrm{H}_{22} \mathrm{~N}_{2}^{+}: 278.1783(44.3 \mathrm{ppm})$. HPLC-MS (gradient 80) $\mathrm{m} / \mathrm{z} 277.1\left([\mathrm{M}-\mathrm{H}-\mathrm{TfO}-\mathrm{I}]^{+}\right.$); retention time $4.4 \mathrm{~min}$. $\mathbf{R}_{\mathbf{f}}: 0.5\left(\mathrm{RP}-18 \mathrm{SiO}_{2} ; \mathrm{MeCN} / \mathrm{H}_{2} \mathrm{O} / \mathrm{TFA}-80: 20: 0.1\right)$. Solubility in water: $\geq 114 \mathrm{mM}$.

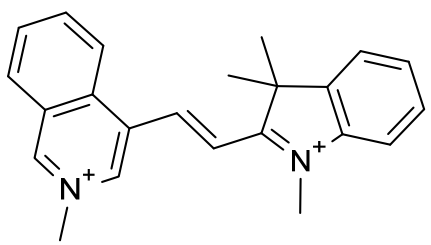

Compound 5 (97 mg, $0.16 \mathrm{mmol}$ ) was obtained following the general procedure II, from a mixture of indolium salt 18 $(100 \mathrm{mg}, 0.23 \mathrm{mmol})$ in DCM $(10 \mathrm{~mL})$ and TfOMe $(129 \mu \mathrm{L}, 1.14 \mathrm{mmol})$ under Ar. MF: $\mathrm{C}_{23} \mathrm{H}_{24} \mathrm{~N}_{2}\left(\mathrm{CF}_{3} \mathrm{O}_{3} \mathrm{~S} ; \mathrm{I}\right)$. FW: 604.43. Yield: 70\%. Physical State: yellow powder. ${ }^{1} \mathbf{H}$ NMR (DMSO-d $\left.{ }_{6}, 400 \mathrm{MHz}\right): \delta(\mathrm{ppm}) 10.10(\mathrm{~s}, 1 \mathrm{H}), 9.35$ (s, 1 
H), $8.86(\mathrm{~d}, J=16.4 \mathrm{~Hz}, 1 \mathrm{H}), 8.67(\mathrm{~d}, J=8.3 \mathrm{~Hz}, 1 \mathrm{H}), 8.60(\mathrm{~d}, J=8.3 \mathrm{~Hz}, 1 \mathrm{H}), 8.42(\mathrm{dd}, J=8.3,7.7 \mathrm{~Hz}, 1 \mathrm{H}), 8.19$ (dd, $J=8.3,7.7 \mathrm{~Hz}, 1 \mathrm{H}), 8.02-8.08(\mathrm{~m}, 1 \mathrm{H}), 7.95-8.00(\mathrm{~m}, 1 \mathrm{H}), 7.89$ (d, $J=16.4 \mathrm{~Hz}, 1 \mathrm{H}), 7.69-7.77$ (m, $2 \mathrm{H}), 4.56$ (s, $3 \mathrm{H}$ ), 4.28 (s, $3 \mathrm{H}), 1.88$ (s, $6 \mathrm{H}$ ). ${ }^{13} \mathbf{C}$ NMR (DMSO-d $\left.{ }_{6}, 101 \mathrm{MHz}\right): \delta$ (ppm) 181.7, 152.3, 143.9, 141.9, 141.7, 137.8, 135.5, 134.1, 131.7, 131.3, 130.6, 130.3, 129.3, 127.2, 124.3, 123.2, 120.7 (q, $J=322 \mathrm{~Hz}, \mathrm{TfO}), 120.5,116.2,53.1$, 48.3, 35.6, 24.5 (2C). HRMS: $m / z 164.0968\left([\mathrm{M}-\mathrm{TfO}-\mathrm{I}]^{2+}\right)$ calculated for $\mathrm{C}_{23} \mathrm{H}_{24} \mathrm{~N}_{2}{ }^{2+}: 164.0969(\Delta-0.6 \mathrm{ppm})$. HPLC-MS (gradient 80$) \mathrm{m} / \mathrm{z} 327.2\left([\mathrm{M}-\mathrm{H}-\mathrm{TfO}-\mathrm{I}]^{+}\right)$; retention time $5.3 \mathrm{~min}$. Solubility in water: $\geq 25 \mathrm{mM}$.

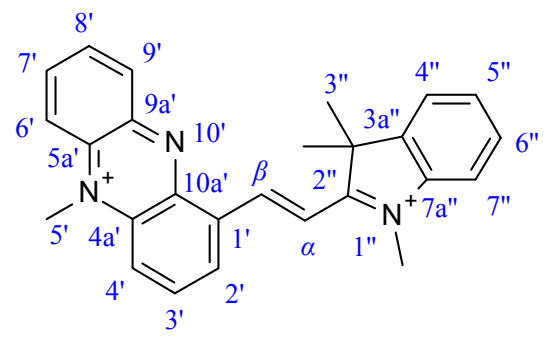

Compound 6 ( $81 \mathrm{mg}, 0.12 \mathrm{mmol}$ ) was obtained following the general procedure II, from a suspension of indolium salt 19 (300 mg, $0.61 \mathrm{mmol})$ in DCM $(50 \mathrm{~mL})$ and TfOMe (345 $\mu \mathrm{L}, 3.05 \mathrm{mmol})$ under Ar. MF: $\mathrm{C}_{26} \mathrm{H}_{25} \mathrm{~N}_{3}\left(\mathrm{CF}_{3} \mathrm{O}_{3} \mathrm{~S} ; \mathrm{I}\right)$. FW: 655.47. Yield: $20 \%$. Physical State: orange powder. ${ }^{1} \mathbf{H}$ NMR (MeOD-d $\mathrm{d}_{3}, 500 \mathrm{MHz}, \mathrm{HMBC}, \mathrm{HSQC}$, TOCSY, NOESY): $\delta(\mathrm{ppm}) 9.73\left(\mathrm{~d}, J=16.7 \mathrm{~Hz}, 1 \mathrm{H}, \mathrm{C}^{\beta} \mathrm{H}\right), 9.17\left(\mathrm{~d}, J=7.3 \mathrm{~Hz}, 1 \mathrm{H}, \mathrm{C}^{2} \mathrm{H}\right), 9.06\left(\mathrm{~d}, J=9.1 \mathrm{~Hz}, 1 \mathrm{H}, \mathrm{C}^{4} \mathrm{H}\right), 8.92(\mathrm{~d}$, $\left.J=9.1 \mathrm{~Hz}, 1 \mathrm{H}, \mathrm{C}^{6^{\prime}} \mathrm{H}\right), 8.85\left(\mathrm{~d}, J=8.5 \mathrm{~Hz}, 1 \mathrm{H}, \mathrm{C}^{9} \mathrm{H}\right), 8.68\left(\mathrm{dd}, J=9.1,7.3 \mathrm{~Hz}, 1 \mathrm{H}, \mathrm{C}^{3} \mathrm{H}\right), 8.62(\mathrm{dd}, J=9.1,6.8 \mathrm{~Hz}, 1 \mathrm{H}$, $\left.\mathrm{C}^{7^{\prime}} \mathrm{H}\right), 8.42\left(\mathrm{dd}, J=8.5,6.8 \mathrm{~Hz}, 1 \mathrm{H}, \mathrm{C}^{8^{\prime}} \mathrm{H}\right), 8.31$ (d, $\left.J=16.7 \mathrm{~Hz}, 1 \mathrm{H}, \mathrm{C}^{\alpha} \mathrm{H}\right), 7.98$ (d, $\left.J=7.3 \mathrm{~Hz}, 1 \mathrm{H}, \mathrm{C}^{7{ }^{7}} \mathrm{H}\right), 7.90$ (d, $\left.J=7.3 \mathrm{~Hz}, 1 \mathrm{H}, \mathrm{C}^{4 "} \mathrm{H}\right), 7.69-7.79\left(\mathrm{~m}, 2 \mathrm{H}, \mathrm{C}^{5 "} \mathrm{H}\right.$ and $\left.\mathrm{C}^{6 "} \mathrm{H}\right), 5.14$ (s, 3H, $\left.N^{1} \mathrm{Me}\right), 4.37$ (s, 3H, $\left.N^{1 "} \mathrm{Me}\right), 2.03(\mathrm{~s}, 6 \mathrm{H}$, $\left.\mathrm{C}^{3 "} \mathrm{Me}_{2}\right) .{ }^{13} \mathrm{C}$ NMR (MeOD-d $\left.3,126 \mathrm{MHz}, \mathrm{HMBC}, \mathrm{HSQC}\right): \delta(\mathrm{ppm}) 184.3\left(\mathrm{C}_{\mathrm{q}}\right), 146.5\left(\mathrm{C}^{\beta} \mathrm{H}\right), 145.5\left(\mathrm{C}_{\mathrm{q}}\right), 144.7\left(\mathrm{C}_{\mathrm{q}}\right)$, $143.5\left(\mathrm{C}_{\mathrm{q}}\right), 142.1\left(\mathrm{C}^{7^{\prime}} \mathrm{H}\right), 140.4\left(\mathrm{C}^{3^{\prime}} \mathrm{H}\right), 136.5\left(\mathrm{C}_{\mathrm{q}}\right), 135.3\left(\mathrm{C}_{\mathrm{q}}\right), 135.1\left(\mathrm{C}_{\mathrm{q}}\right), 134.6\left(\mathrm{C}^{8^{\prime}} \mathrm{H}\right), 133.9\left(\mathrm{C}^{9} \mathrm{H}\right), 133.0\left(\mathrm{C}^{2} \mathrm{H}\right), 132.2$ $\left(\mathrm{C}^{5^{\prime \prime}} \mathrm{H}\right), 131.0\left(\mathrm{C}^{6^{\prime \prime}} \mathrm{H}\right), 124.3\left(\mathrm{C}^{4^{\prime \prime}} \mathrm{H}\right), 123.6\left(\mathrm{C}^{4} \mathrm{H}\right), 120.3\left(\mathrm{C}^{6^{\prime}} \mathrm{H}\right), 119.4\left(\mathrm{C}^{\alpha} \mathrm{H}\right), 117.0\left(\mathrm{C}^{7 "} \mathrm{H}\right), 54.8\left(\mathrm{C}_{\mathrm{q}}\right), 40.5\left(N^{5^{\prime}} \mathrm{Me}\right), 35.8$ $\left(N^{1 "} \mathrm{Me}\right), 26.4\left(\mathrm{C}^{3 "} \mathrm{Me}_{2}\right)$. HRMS: $m / z$ 379.2048 ([M - TfO - I $\left.]^{+}\right)$calculated for $\mathrm{C}_{26} \mathrm{H}_{25} \mathrm{~N}_{3}^{+}: 379.2048$ ( $\left.40.0 \mathrm{ppm}\right) . \mathbf{R}_{\mathbf{f}}: 0.3$ (RP-18 $\left.\mathrm{SiO}_{2} ; \mathrm{MeCN} / \mathrm{H}_{2} \mathrm{O} / \mathrm{TFA}-80: 20: 0.1\right)$. Solubility in water: $\geq 4 \mathrm{mM}$. Note. In case of a sample dissolved in DMSO- $\mathrm{d}_{6}$, under the same concentration and settings, ${ }^{1} \mathrm{H}$ NMR signals were not observed. 


\section{Synthesis and Structure Confirmation of the Cyanine Chromophore}<smiles>CN1C=C(/C=C/C2=[N+](C)c3ccccc3C2(C)C)Cc2ccccc21</smiles>

The MQ-water solution $(7 \mathrm{~mL})$ of $\mathbf{1}(19.2 \mathrm{mg}, 0.032 \mathrm{mmol})$ was mixed with a buffered aqueous solution $(3 \mathrm{~mL}$, $\mathrm{pH}=7.0)$ of NADH $(27.4 \mathrm{mg}, 0.039 \mathrm{mmol})$ at $\mathrm{rt}$. The reaction mixture was stirred for $2 \mathrm{~h}$ after which the organic product was extracted into DCM. After drying $\left(\mathrm{Na}_{2} \mathrm{SO}_{4}\right)$, the solvent was removed on the rotary evaporator to give $\mathbf{1 C y}(14.3$ $\mathrm{mg}, 0.031 \mathrm{mmol})$.

MF: C23H25N2-I. FW: 456.36. Yield: 98\%. Physical State: dark pink solid.

${ }^{1}$ H NMR (MeCN-d $\left.{ }_{3}, 400 \mathrm{MHz}, \mathrm{COSY}, \mathrm{HSQC}, \mathrm{HMBC}\right): \delta(\mathrm{ppm}) 7.98(\mathrm{dt}, J=14.4,1.5 \mathrm{~Hz}, 1 \mathrm{H}), 7.70(\mathrm{~s}, 1 \mathrm{H}), 7.50-7.55$ (m, 1H), 7.43-7.49 (m, 1H), 7.34 (ddd, $J=7.9,7.6,1.0 \mathrm{~Hz}, 1 \mathrm{H}), 7.27-7.35(\mathrm{~m}, 3 \mathrm{H}), 7.23-7.26(\mathrm{~m}, 1 \mathrm{H})$, 7.19-7.23 (m, 1H), $5.92(\mathrm{~d}, J=14.4 \mathrm{~Hz}, 1 \mathrm{H}), 3.96(\mathrm{~d}, J=1.5 \mathrm{~Hz}, 2 \mathrm{H}), 3.64(\mathrm{~s}, 3 \mathrm{H}), 3.54(\mathrm{~s}, 3 \mathrm{H}), 1.69$ (s, 6H). ${ }^{13} \mathbf{C}$ NMR $\left(\mathrm{MeCN}_{3}\right.$, 400MHz, HSQC, HMBC): $\delta$ (ppm) 176.6, 154.5, 153.1, 142.7, 141.4, 136.4, 130.0, 128.6, 127.8, 126.5, 125.9, 124.6,

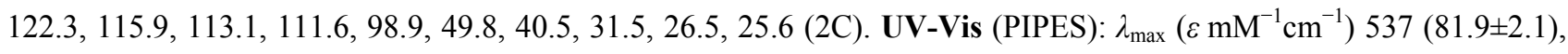
515sh. (59.2 \pm 1.3$) \mathrm{nm}$. HPLC-MS (gradient 80): $\mathrm{m} / \mathrm{z} 329.19$ ([M - I $]^{+}$); retention time $6.8 \mathrm{~min}$. Note. The assignment of resonances is given in Table S2. 


\section{Supplementary Tables}

Table S1. Spectral properties and NADH-response screening of compounds 1-6.

\begin{tabular}{lll}
\hline Entry & $\lambda_{\max }\left(\varepsilon \mathrm{mM}^{-1} \mathrm{~cm}^{-1}\right), \mathrm{nm}$ & $\lambda_{\max }, \mathrm{nm}($ with NADH) \\
\hline $\mathbf{1}$ & $512(0.8), 384(19.5), 312(13.5)$ & $537,515 \mathrm{sh}$. \\
$\mathbf{2}$ & $383(22.8), 340(14.1)$ & - \\
$\mathbf{3}$ & $379(23.2), 318(15.9)$ & 517 \\
$\mathbf{4}$ & $363(11.7), 291(9.2), 251(10.7)$ & $546,534 \mathrm{sh}$. \\
$\mathbf{5}$ & $514 \mathrm{sh} .(1.9), 487(3.7), 372(12.6), 345(12.3)$ & $524 \mathrm{sh} ., 499$ \\
$\mathbf{6}$ & $481(6.0), 394(16.2), 377 \mathrm{sh} .(15.6), 261(26.4)$ & 740 \\
\hline
\end{tabular}


Table S2. ${ }^{1} \mathrm{H}(400 \mathrm{MHz})$ and ${ }^{13} \mathrm{C}(100 \mathrm{MHz}) \mathrm{NMR}$ signal assignment for $\mathbf{1}$ and $\mathbf{1 C y}$ in $\mathrm{MeCN}-\mathrm{d}_{3} \cdot{ }^{*}$

\begin{tabular}{|c|c|c|c|c|}
\hline \multirow{2}{*}{ Position } & \multicolumn{2}{|l|}{ Indicator 1} & \multicolumn{2}{|l|}{ Chromophore 1Cy } \\
\hline & $\delta^{1} \mathrm{H}(\mathrm{ppm}) ; J(\mathrm{~Hz})$ & $\delta{ }^{13} \mathrm{C}(\mathrm{ppm})$ & $\delta^{1} \mathrm{H}(\mathrm{ppm}) ; J(\mathrm{~Hz})$ & $\delta^{13} \mathrm{C}(\mathrm{ppm})$ \\
\hline \multicolumn{5}{|c|}{ Quinolinium moiety } \\
\hline$N^{1} \mathrm{Me}$ & $4.69 ; \mathrm{s}$ & 47.5 & $3.54 ; \mathrm{s}$ & 40.5 \\
\hline $2^{\prime}$ & $9.73 ; \mathrm{d}, 1.2$ & 151.4 & $7.70 ; \mathrm{s}$ & 154.5 \\
\hline $3^{\prime}$ & - & 129.6 & - & 113.1 \\
\hline $4^{\prime}$ & $9.65 ; \mathrm{d}, 1.2$ & 148.4 & $3.96 ; \mathrm{d}, 1.5$ & 25.6 \\
\hline $4 a^{\prime}$ & - & 130.8 & - & 124.6 \\
\hline $5^{\prime}$ & $8.44 ; \mathrm{dd}, 9.0,0.6$ & 133.1 & $7.27-7.35 ; \mathrm{m}$ & 130.0 \\
\hline $6^{\prime}$ & 8.36; ddd, 9.0, 7.0, 1.5 & 139.1 & $7.19-7.23 ; \mathrm{m}$ & 115.9 \\
\hline $7^{\prime}$ & $8.13 ;$ ddd, $8.2,7.0,0.6$ & 132.7 & $7.27-7.35 ; \mathrm{m}$ & 127.8 \\
\hline $8^{\prime}$ & $8.49 ; \mathrm{dd}, 8.2,1.5$ & 120.5 & $7.23-7.26 ; \mathrm{m}$ & 126.5 \\
\hline $8 a^{\prime}$ & - & 140.5 & - & 136.4 \\
\hline \multicolumn{5}{|c|}{ Vinyl bridge } \\
\hline$\alpha$ & $7.81 ; \mathrm{d}, 16.5$ & 119.1 & $5.92 ; \mathrm{d}, 14.4$ & 98.9 \\
\hline$\beta$ & $8.38 ; \mathrm{d}, 16.5$ & 145.9 & $7.98 ; \mathrm{dt}, 14.4,1.5$ & 153.1 \\
\hline \multicolumn{5}{|c|}{ Indolium moiety } \\
\hline$N^{1 "} \mathrm{Me}$ & $4.21 ; \mathrm{s}$ & 36.7 & $3.64 ; \mathrm{s}$ & 31.5 \\
\hline $2^{\prime \prime}$ & - & 183.5 & - & 176.6 \\
\hline 3" & - & 54.7 & - & 49.8 \\
\hline $\mathrm{C}^{3 "} \mathrm{Me}_{2}$ & $1.85 ; \mathrm{s}$ & 25.7 & $1.69 ; \mathrm{s}$ & 26.5 \\
\hline 3a" & - & 145.4 & - & 141.4 \\
\hline $4 "$ & 7.82-7.86; m & 117.2 & $7.50-7.55 ; \mathrm{m}$ & 122.3 \\
\hline $5^{\prime \prime}$ & 7.73; ddd, 7.4, 7.3, 1.4 & 132.4 & 7.34; ddd, 7.9, 7.6, 1.0 & 125.9 \\
\hline 6" & 7.70; ddd, 7.6, 7.3, 1.6 & 131.0 & $7.43-7.49 ; \mathrm{m}$ & 128.6 \\
\hline 7" & $7.78-7.82 ; \mathrm{m}$ & 124.4 & $7.27-7.35 ; \mathrm{m}$ & 111.6 \\
\hline 7a" & - & 143.2 & - & 142.7 \\
\hline
\end{tabular}

*For the numbering, see below.
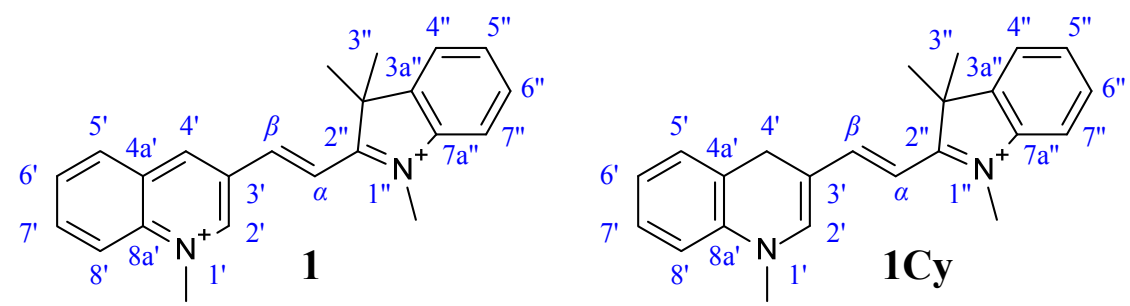


\section{Supplementary Figures}

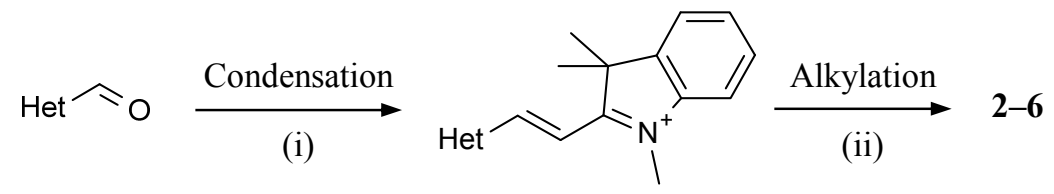

Heterocycles (entry):

Heterocycles (entry):

$\begin{array}{ll}\text { 5-quinolyl (10) } & \text { 5-quinolyl (15) } \\ \text { 6-quinolyl (11) } & \text { 6-quinolyl (16) } \\ \text { 3-pyridyl (12) } & \text { 3-pyridyl (17) } \\ \text { 3-isoquinolyl (13) } & \text { 3-isoquinolyl (18) } \\ \text { 1-phenazyl (14) } & \text { 1-phenazyl (19) }\end{array}$

Figure S1. Synthesis of compounds 2-6. Reagents and conditions: (i) piperidine (cat.), EtOH, reflux, 2-16 h; (ii) TfOMe (4-10 equiv.), DCM, rt, $16 \mathrm{~h}$.

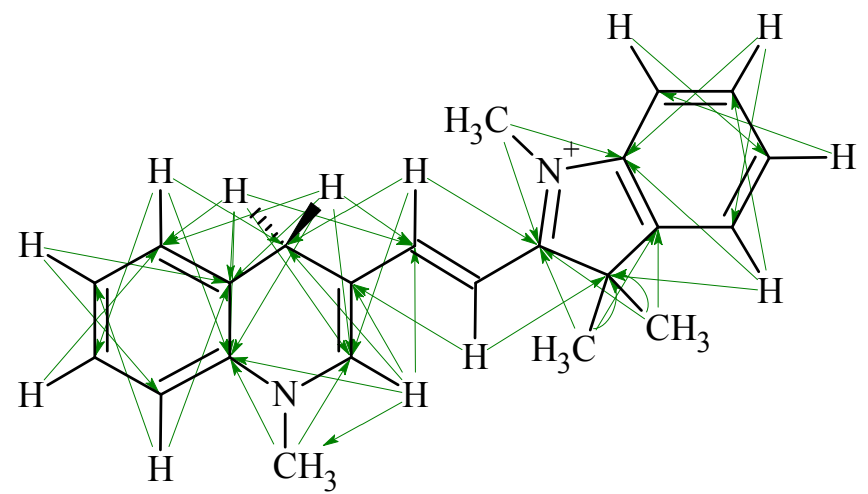

Figure S2. Proton-carbon network of 1Cy established from 2D NMR data (COSY, HSQC, HMBC).

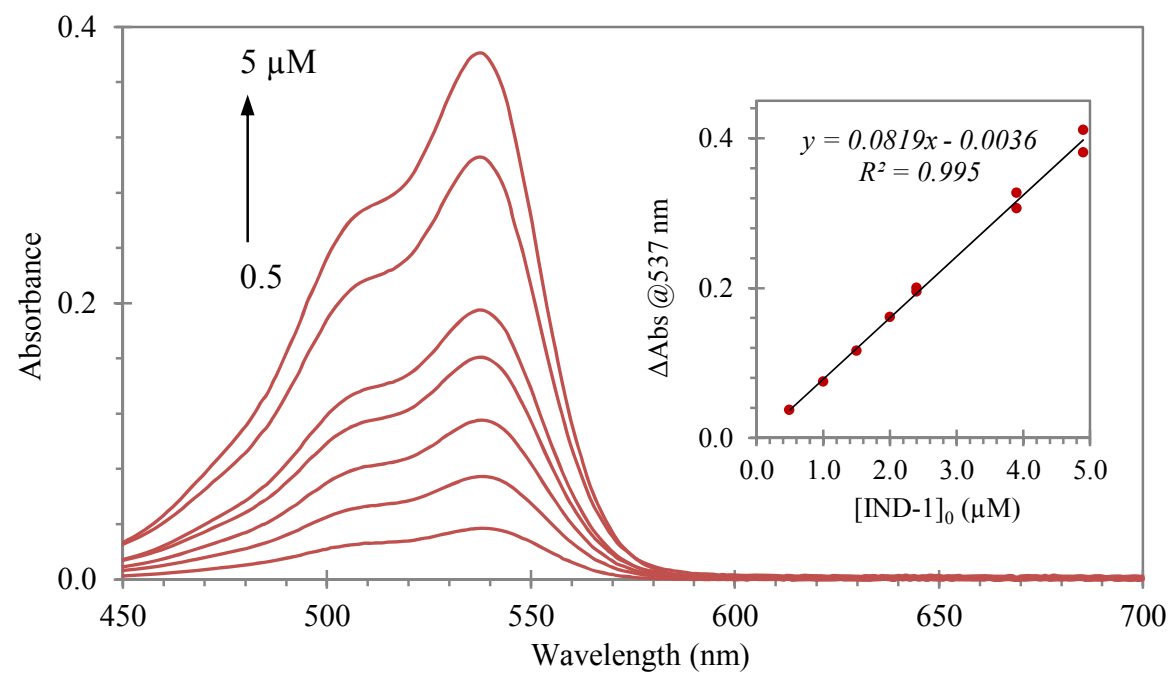

Figure S3. Absorbance responses at $537 \mathrm{~nm}$ of indicator $\mathbf{1}(0.5-5.0 \mu \mathrm{M})$ to the addition of NADH $(500 \mu \mathrm{M})$ in buffer $(25 \mathrm{mM}$ PIPES, $101 \mathrm{mM} \mathrm{NaCl}, \mathrm{pH}$ 7.0). The spectra were taken after incubation for $5 \mathrm{~min}$ at $25^{\circ} \mathrm{C}$. The data are fitted by the following linear equation: $y=0.0819 x-0.0036(n=10)$. 


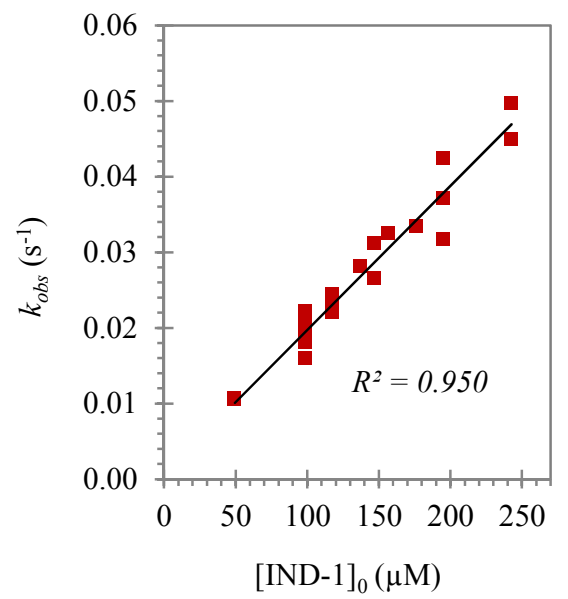

Figure S4. The kinetic study of the response of indicator 1 to NADH at $25^{\circ} \mathrm{C}$ under pseudo-first-order conditions ([IND$\left.1]_{0}=50-250 \mu \mathrm{M},[N A D H]_{0}=5 \mu \mathrm{M}\right)$. The data are fitted by the following linear equation: $y=190.5 \cdot 10^{-6} x+0.0007(n=24)$.

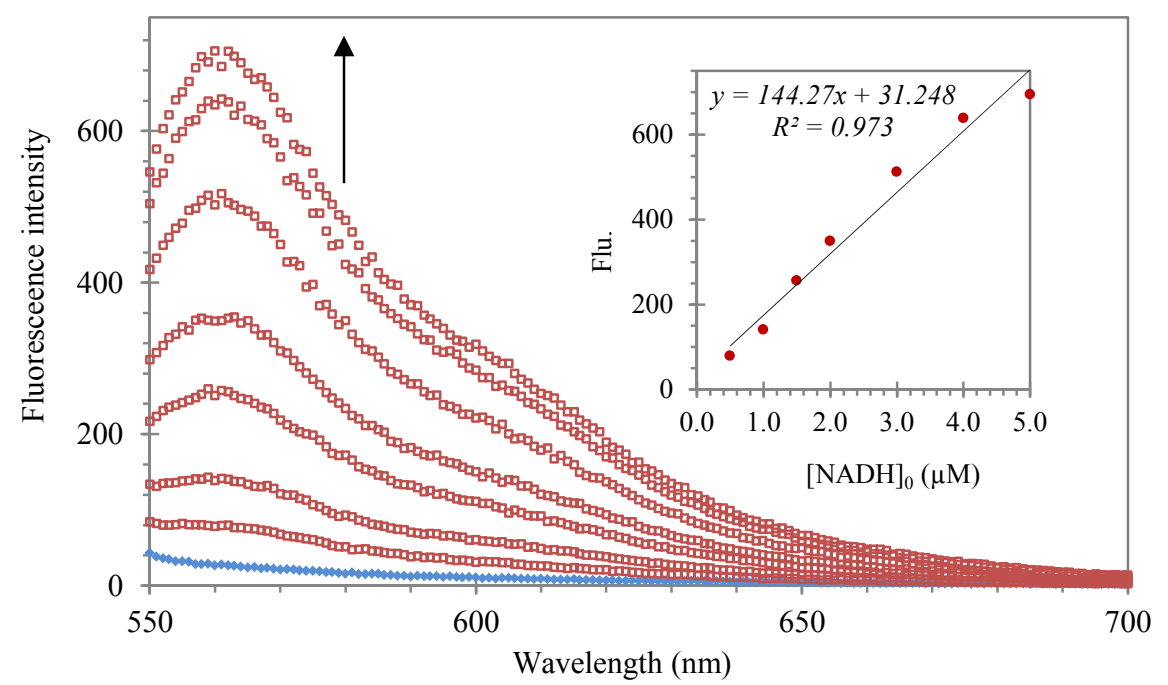

Figure S5. Fluorescence emission response of $1(20 \mu \mathrm{M}$, blue diamonds) to increasing concentrations of NADH (red squares). Inset: relationship between the concentration of NADH and fluorescence intensity (at $561 \mathrm{~nm}$ ) of the reaction mixture. The spectra were taken after incubation for $30 \mathrm{~min}$ in buffer $(25 \mathrm{mM}$ PIPES, $101 \mathrm{mM} \mathrm{NaCl}, \mathrm{pH} 7.0)$ at $25^{\circ} \mathrm{C} . \lambda_{e x}=537 \mathrm{~nm}$, slit widths: $5 / 5 \mathrm{~nm}$.

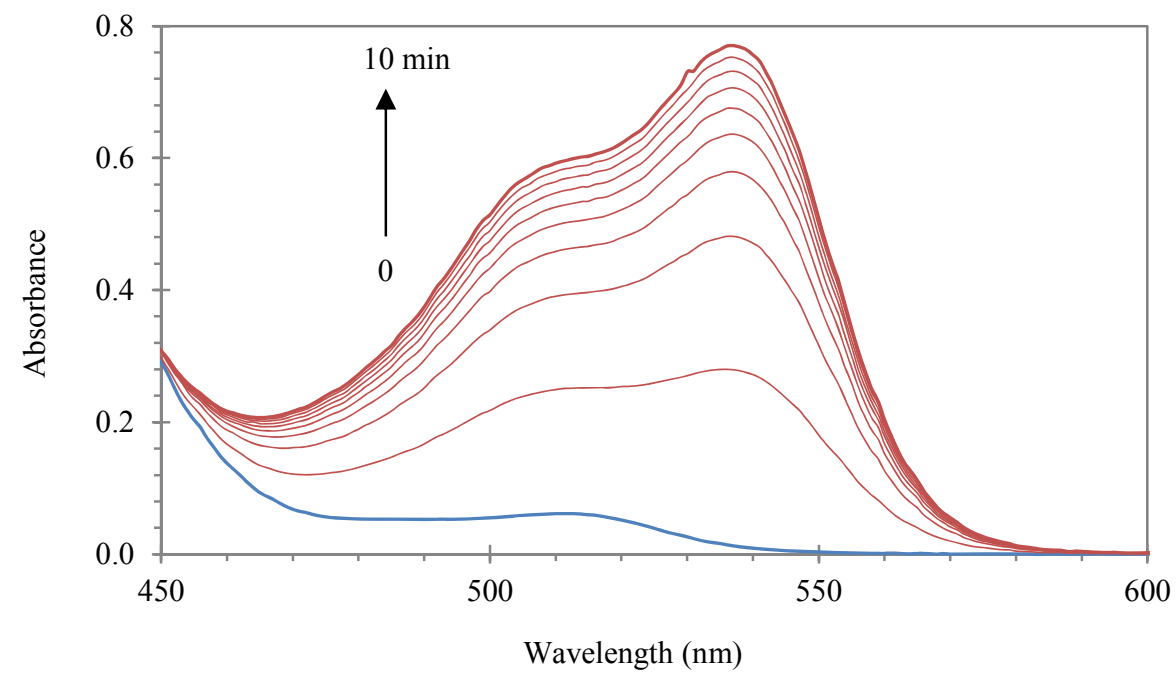

Figure S6. Time-dependent absorbance response of indicator $1(100 \mu \mathrm{M})$ within the enzymatic assay of glucose $(10 \mu \mathrm{M})$ : NAD $(0.4 \mathrm{mM}), \mathrm{GDH}\left(0.1 \mathrm{mg} \mathrm{mL}^{-1}\right)$ in phosphate buffer $(100 \mathrm{mM}, \mathrm{pH} 7.0)$, recorded for $10 \mathrm{~min}$ every $1 \mathrm{~min}$. 


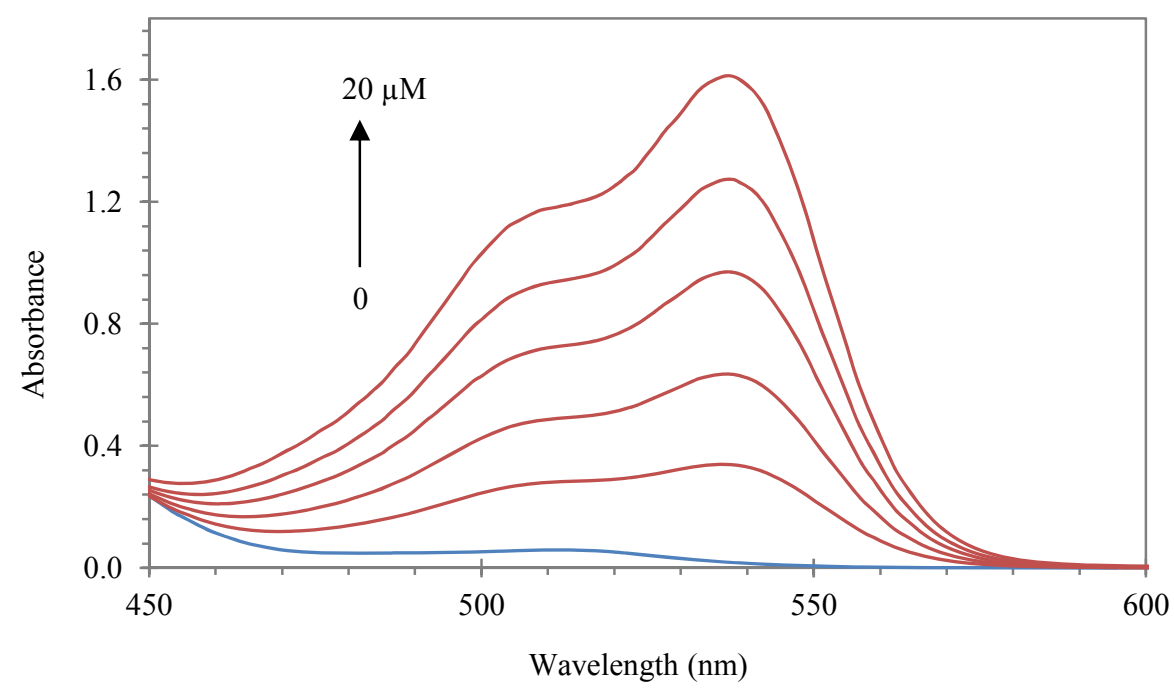

Figure S7. Spectral response of indicator $1(100 \mu \mathrm{M}$, blue $)$ in the assay solution $\left(0.4 \mathrm{mM} \mathrm{NAD}^{+}, 0.1 \mathrm{mg} \mathrm{mL}^{-1}\right.$ in $100 \mathrm{mM}$ phosphate buffer $\mathrm{pH}$ 7.0) to increasing concentrations of glucose $(4.0,8.0,12.0,16.0$ and $20.0 \mu \mathrm{M}$, red), after a fixed reaction time of $10 \mathrm{~min}$.

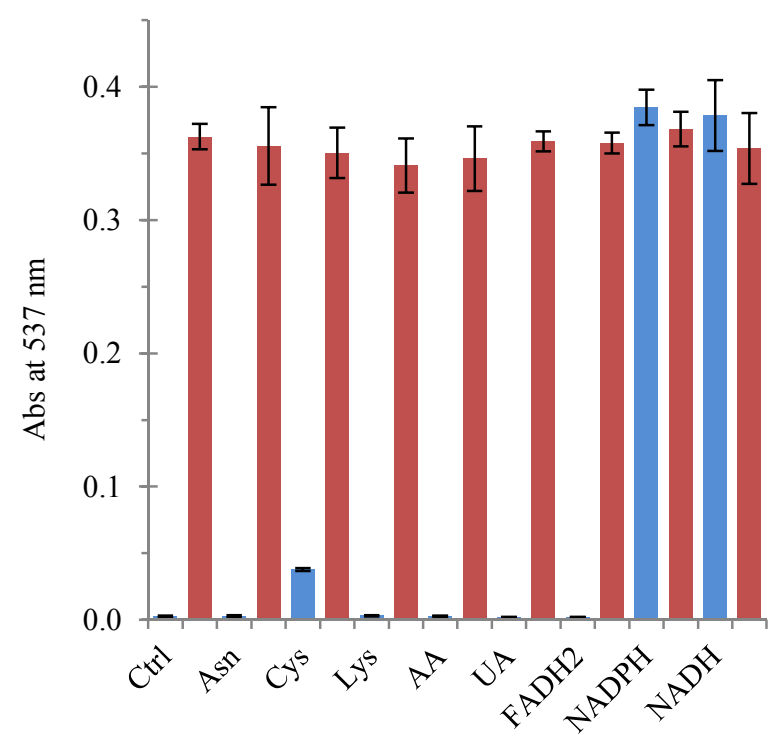

Figure S8. Competitive assays of NADH $(400 \mu \mathrm{M})$ against indicator $1(5 \mu \mathrm{M})$ with various analytes $(400 \mu \mathrm{M})$. From left to right: blank (ctrl), amino acids (Asn, Cys, Lys), ascorbic acid (AA), uric acid (UA), reduced flavin adenine dinucleotide $\left(\mathrm{FADH}_{2}\right)$ and reduced nicotinamide adenine dinucleotides (NADPH, NADH); after 5 min of incubation in buffer (25 mM PIPES, $101 \mathrm{mM} \mathrm{NaCl}, \mathrm{pH}$ 7.0). Blue columns correspond the reaction for $\mathbf{1}+$ analytes; red columns for $\mathbf{1}+$ analytes + NADH. 


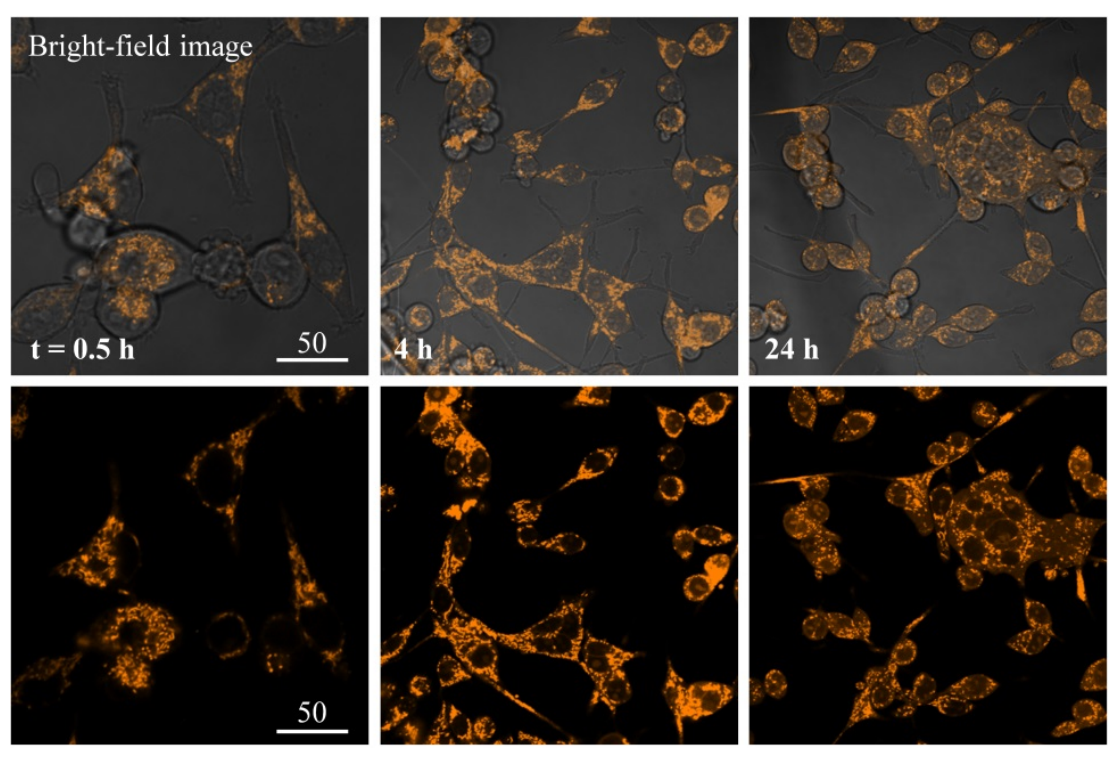

Figure S9. Staining of HEK-293F cells with indicator $1(20 \mu \mathrm{M})$ for different times (indicated). Fluorescence microscopy images with and without transmission light are shown. Scale bar is in $\mu \mathrm{m}$.

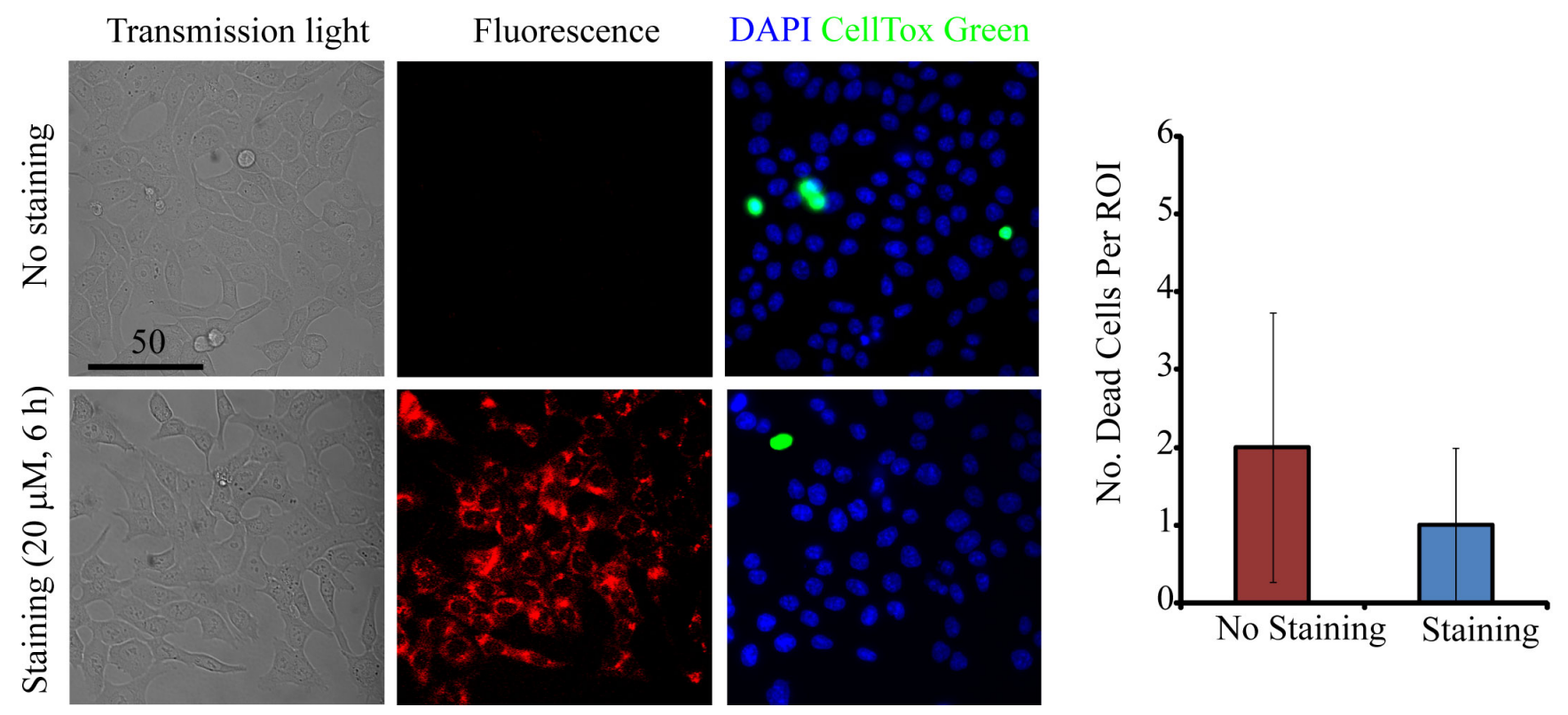

Figure S10. Evaluation of toxicity of $\mathrm{NAD}(\mathrm{P}) \mathrm{H}$ probe in HCT116 cells. Control and tested cells were stained with indicator $\mathbf{1}$ and then incubated with CellTox Green dye $(0.2 \%, 30 \mathrm{~min}$, stains dead cells), analyzed and counted. Staining with DAPI (blue) shows nuclei of viable cells. Scale bar is in $\mu \mathrm{m}$.
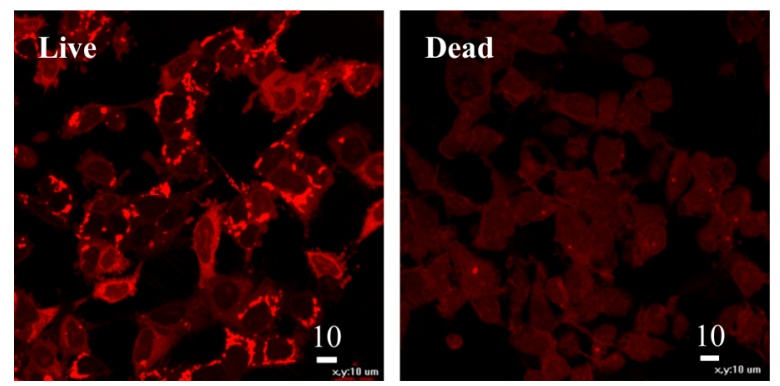

Figure S11. Staining of live and paraformaldehyde-fixed HEK-293 cells stained with indicator 1 (20 $\mu \mathrm{M}, 1 \mathrm{~h})$. Scale bar is in $\mu \mathrm{m}$. 
A)

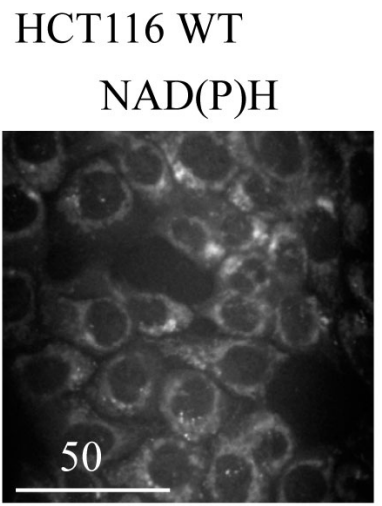

$\mathrm{NAD}(\mathrm{P}) \mathrm{H}$

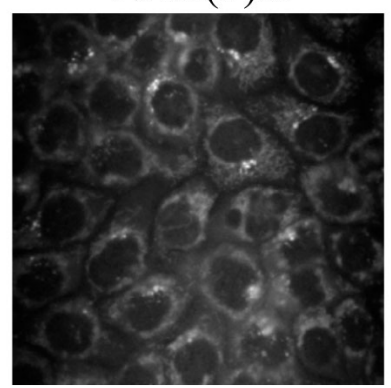

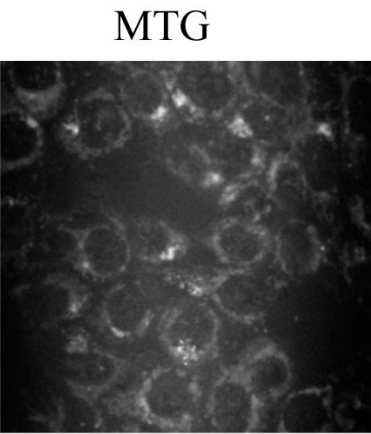

CTX

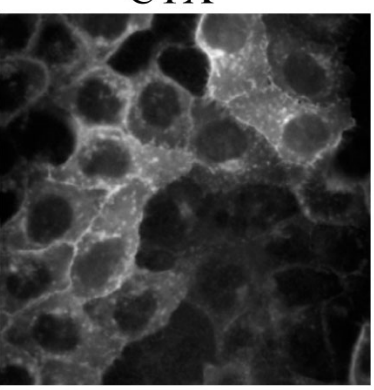

NAD(P)H MTG HXT

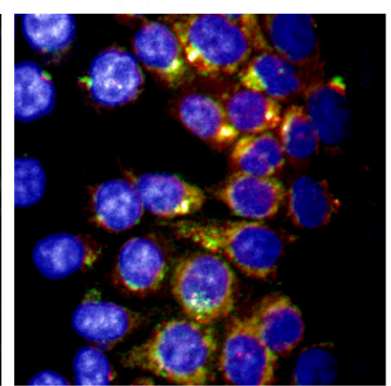

NAD(P)H CTX HXT

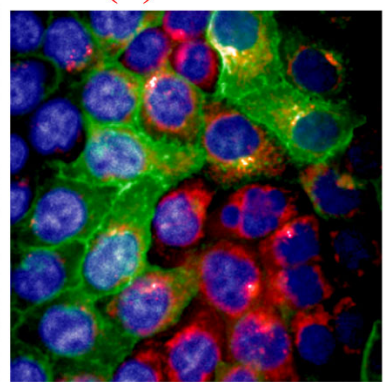

B) HCT116 SCO2-/-
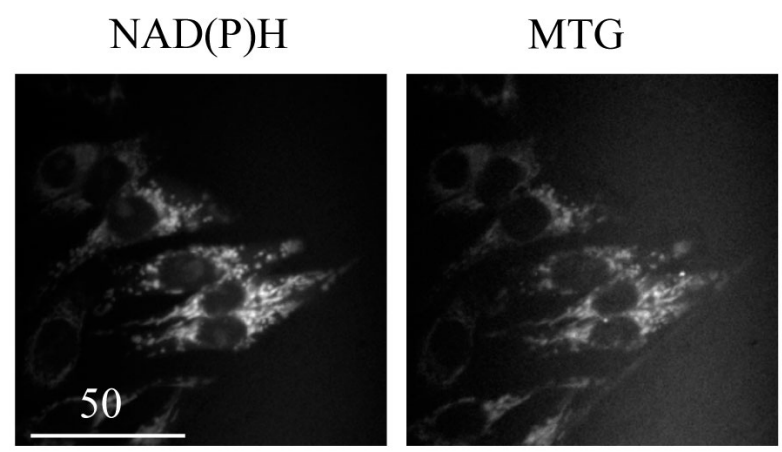

NAD(P)H MTG HXT
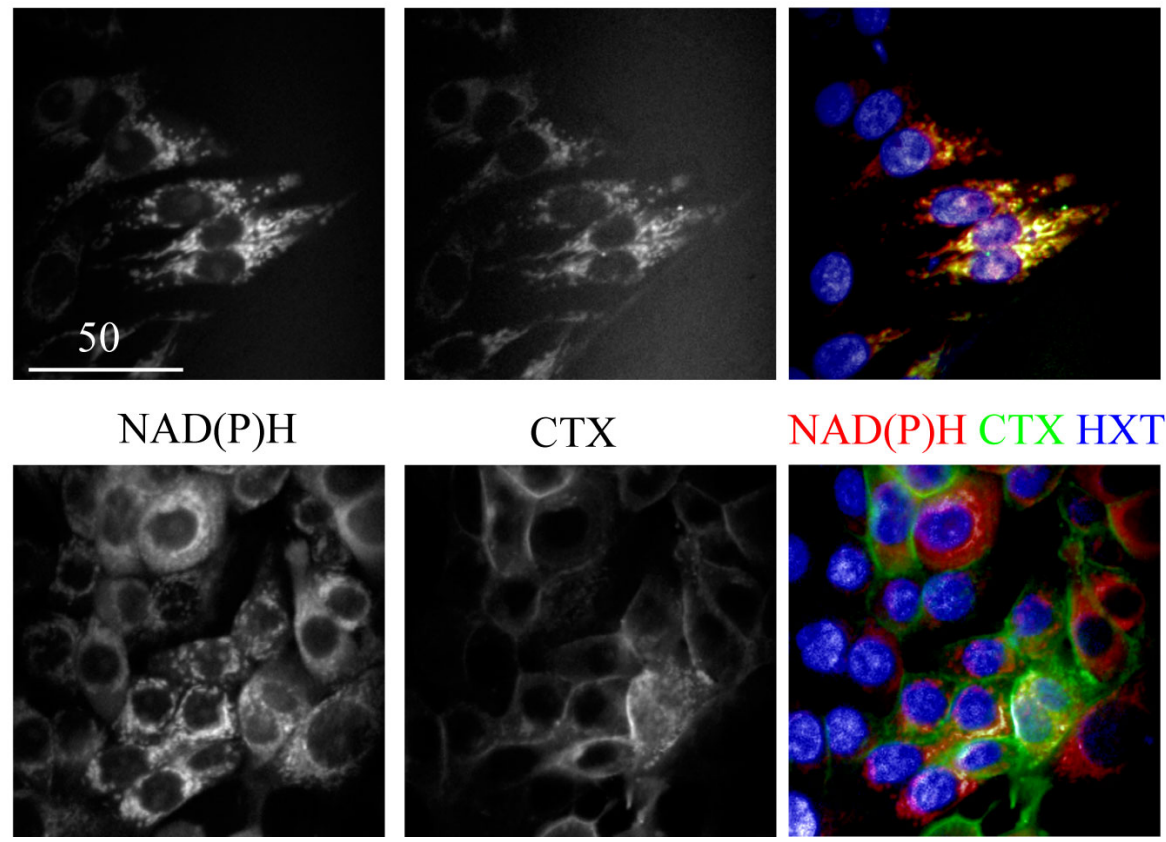

NAD(P)H CTX HXT

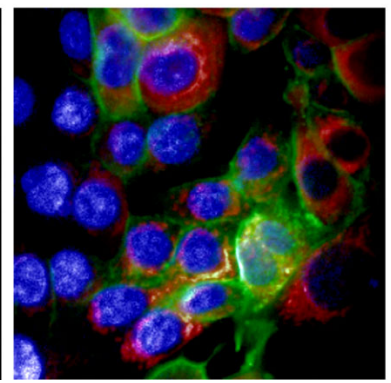

Figure S12. Intracellular localization of indicator 1 (NAD(P)H probe) in HCT116 wild-type (A) and SCO2-/- (B) cells. Adherent cells were stained with indicator 1, counter-stained with marker of nuclei (HXT, blue color), mitochondria (MitoTracker Green, MTG) or endosomes (Cholera toxin-Alexa 488 conjugate, CTX) and imaged on confocal fluorescence microscope. Scale bar is in $\mu \mathrm{m}$. 
A)
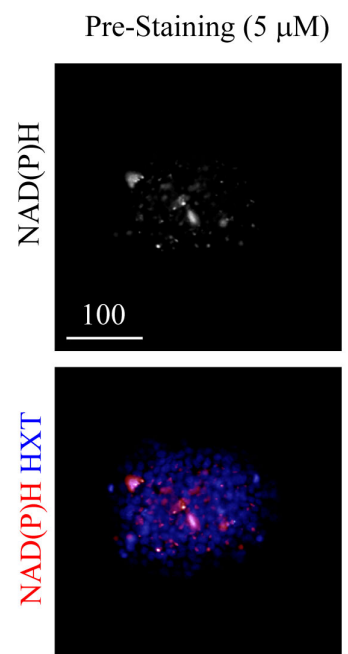

$20 \mu \mathrm{M}, 3 \mathrm{~h}$
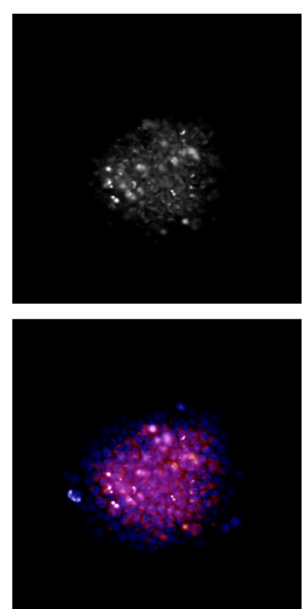

B)

$20 \mu \mathrm{M}, 6 \mathrm{~h}$
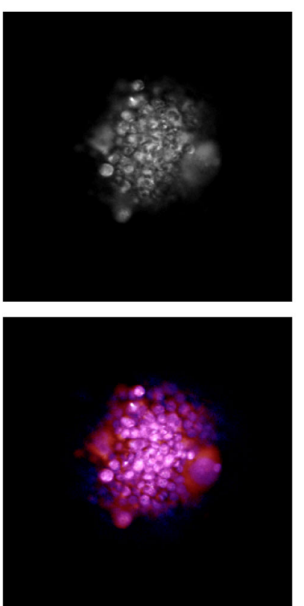

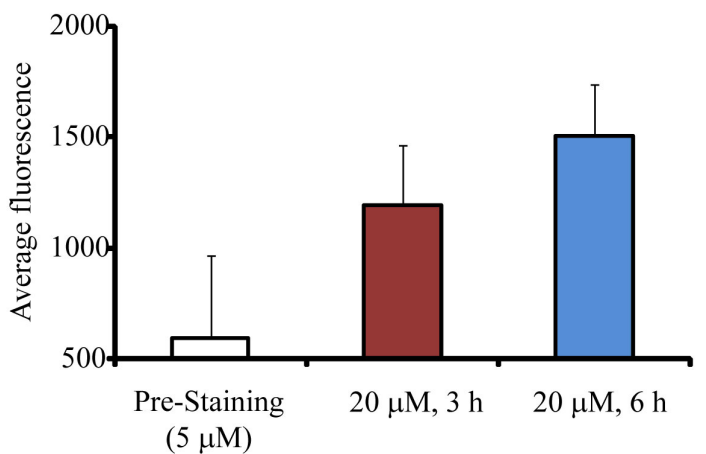

$(5 \mu \mathrm{M})$

Figure S13. Optimization of staining of 3D culture of HCT116 tumor spheroids with indicator 1. The NAD(P)H probe was added either at the moment of seeding of spheroids and incubated for 3 days of forming (pre-staining) or after the formation ( $3,6 \mathrm{~h}$ incubations). (A) Cross-sections are shown, with nuclei visualized using Hoechst 33342 (HXT) and NAD(P)H probe in red. Scale bar is in $\mu \mathrm{m}$. (B) Average fluorescence intensities across stained spheroids. $\mathrm{N}=3$. 


\section{Supplementary NMR spectra}

${ }^{1} \mathrm{H}$ NMR (DMSO- $\mathrm{d}_{6}, 400 \mathrm{MHz}$ ) for 1 iodide trifluoromethanesulfonate salt; S: solvent, W: water

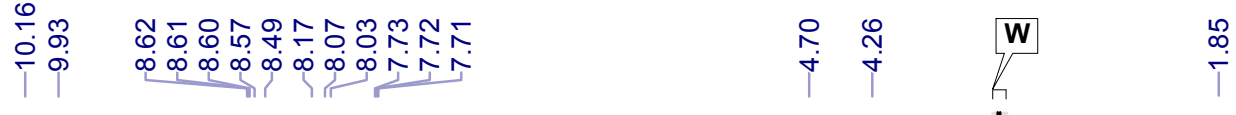<smiles>C[N+]1=C(/C=C/c2cc3ccccc3[n+](C)c2)C(C)(C)c2ccccc21</smiles>
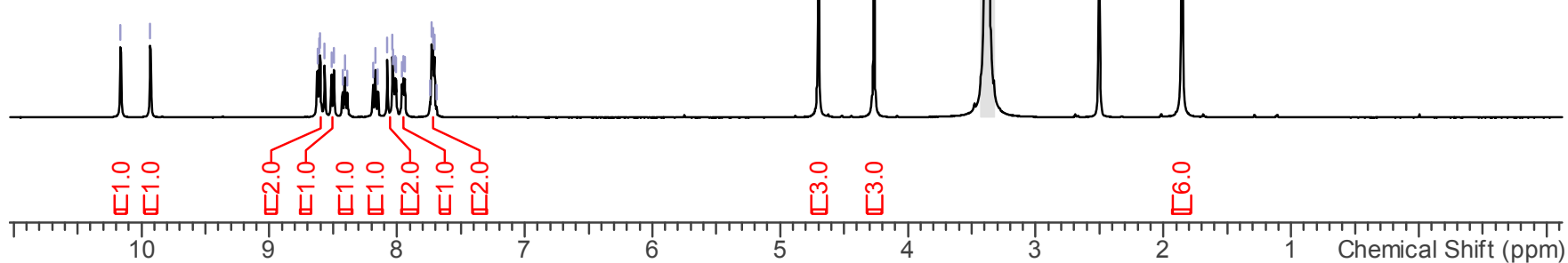

${ }^{13} \mathrm{C}$ NMR (DMSO- $\mathrm{d}_{6}, 100 \mathrm{MHz}$ ) for $\mathbf{1}$ iodide trifluoromethanesulfonate salt; S: solvent

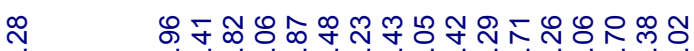

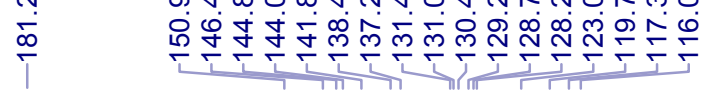<smiles>C[N+]1=C(/C=C/c2cc3ccccc3[n+](C)c2)C(C)(C)c2ccccc21</smiles>

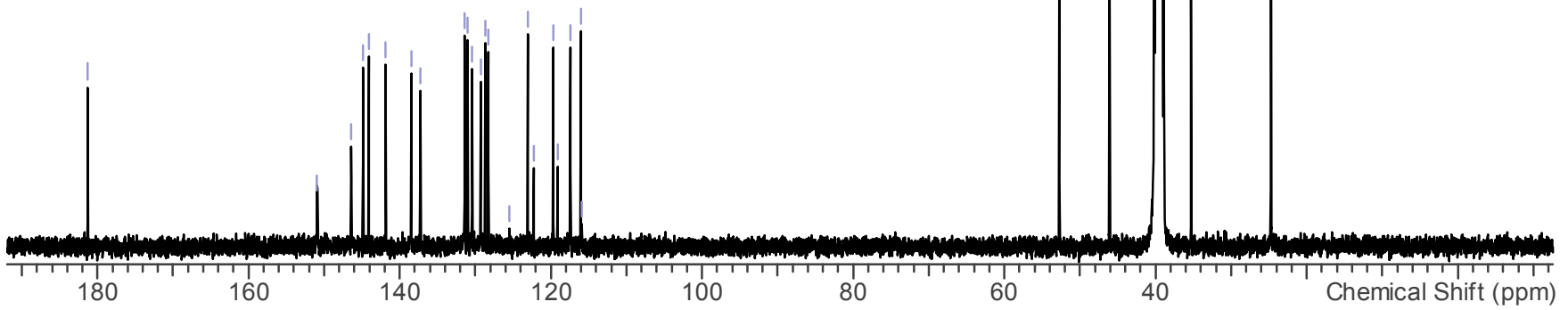


${ }^{1} \mathrm{H}$ NMR (MeCN-d $\mathrm{d}_{3}, 400 \mathrm{MHz}$ ) for $\mathbf{1}$ iodide trifluoromethanesulfonate salt; S: solvent, W: water

꾸요

बंबु

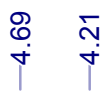

$\stackrel{\substack{\infty \\ \hdashline}}{\infty}$

$\mathrm{W}$<smiles>C[N+]1=C(/C=C/c2cc3ccccc3[n+](C)c2)C(C)(C)c2ccccc21</smiles>

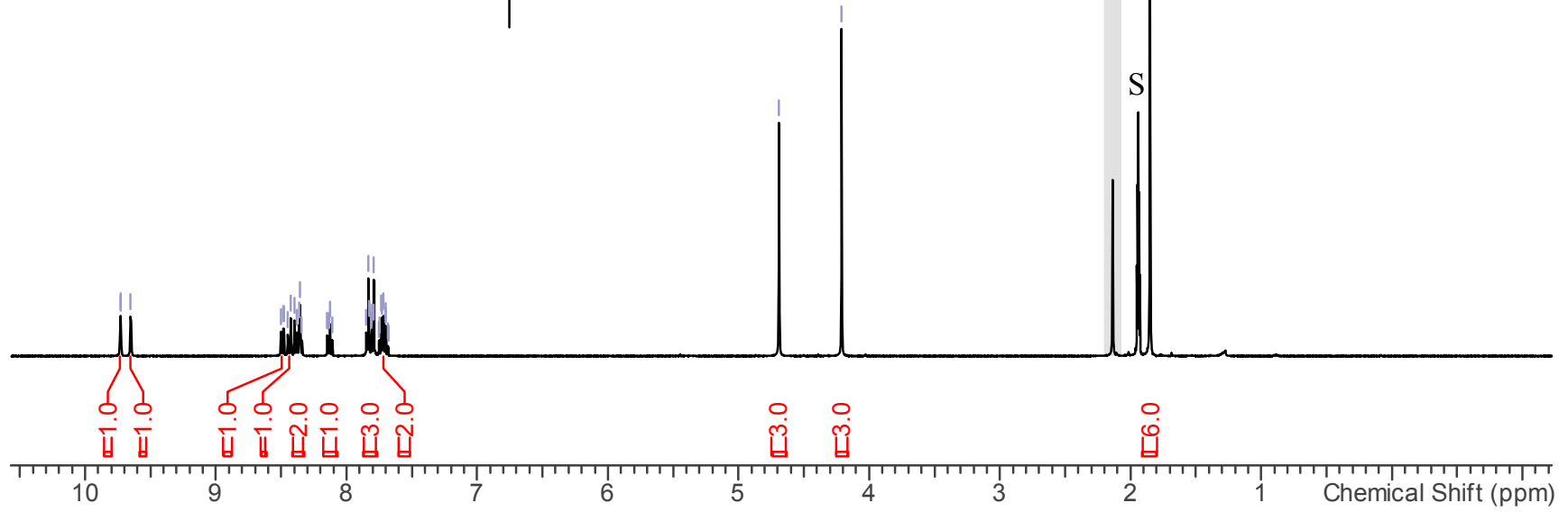

${ }^{13} \mathrm{C}$ NMR (MeCN-d $\mathrm{d}_{3}, 100 \mathrm{MHz}$ ) for $\mathbf{1}$ iodide trifluoromethanesulfonate salt; S: solvent

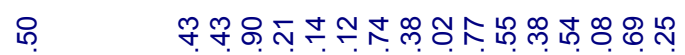

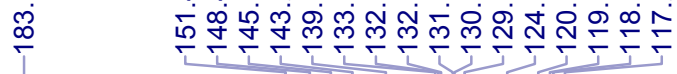

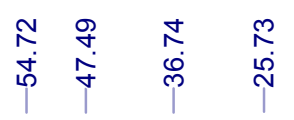

S

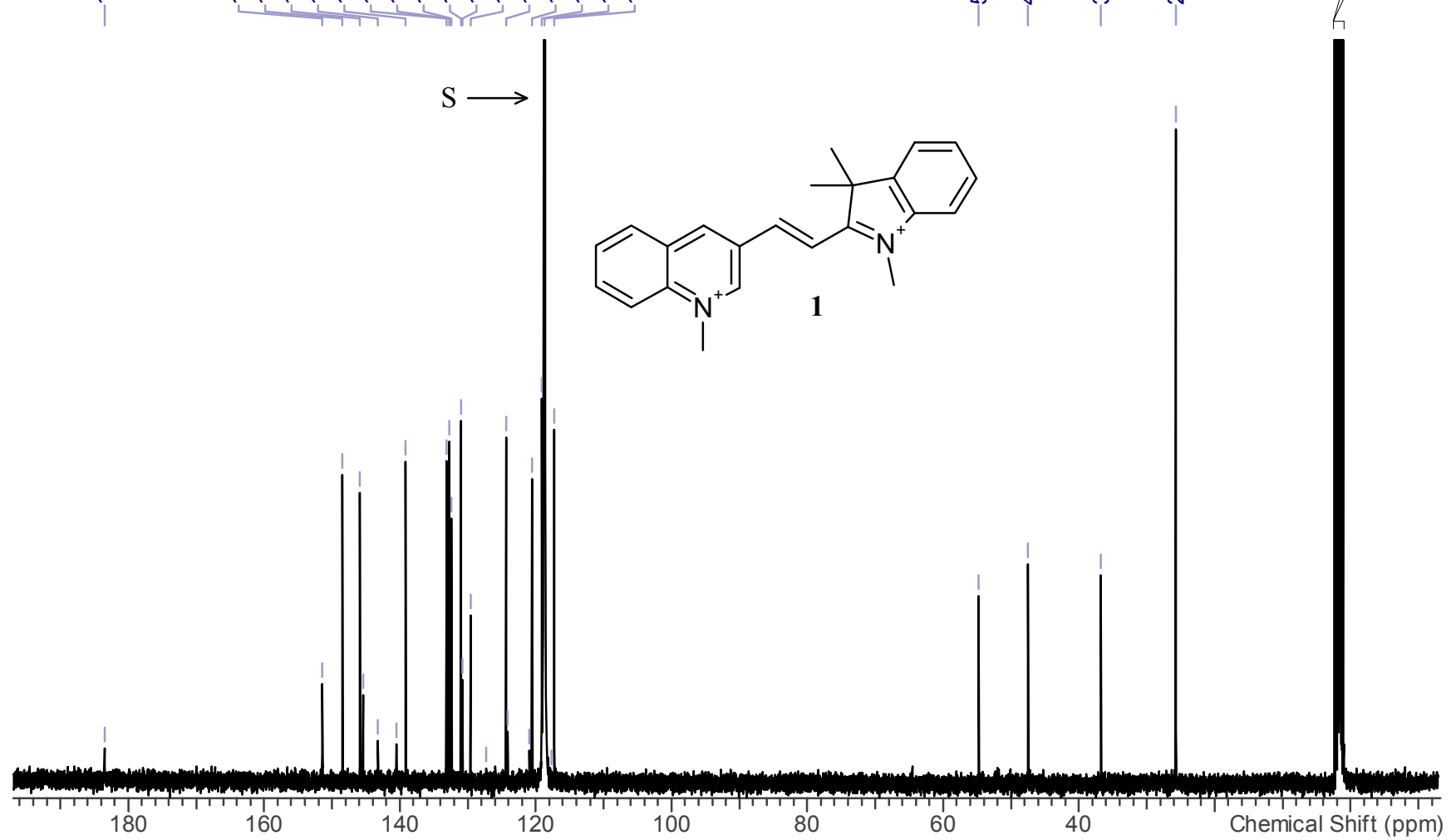


${ }^{1} \mathrm{H}$ NMR $\left(\mathrm{MeCN}_{-} \mathrm{d}_{3}, 400 \mathrm{MHz}\right)$ for $\mathbf{1 C y}$ iodide salt; S: solvent, A: acetone, *: residual grease

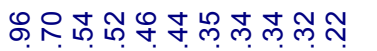

बें क.

\& छे
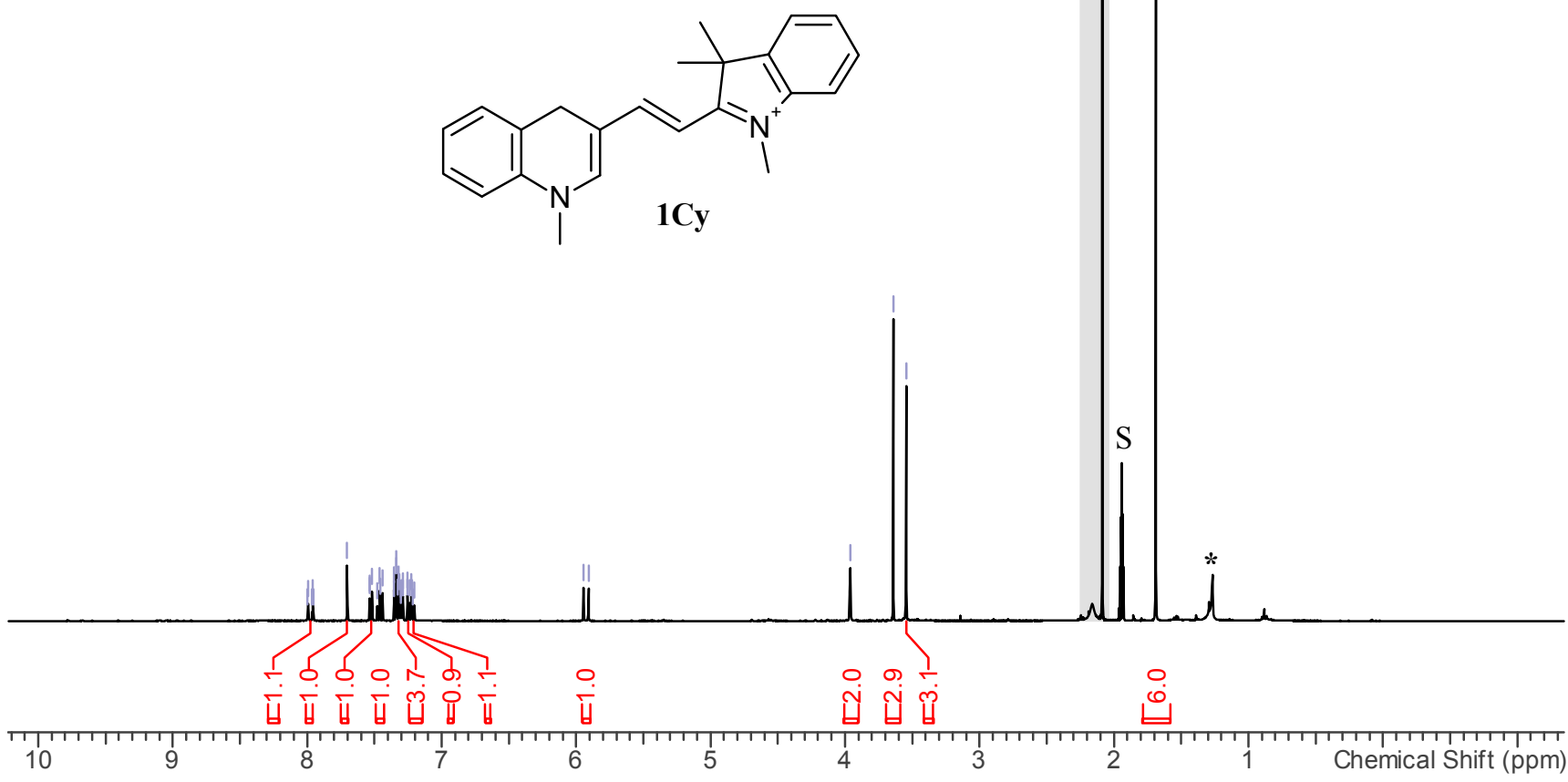

${ }^{13} \mathrm{C}$ NMR $\left(\mathrm{MeCN}_{-} \mathrm{d}_{3}, 100 \mathrm{MHz}\right.$ ) for $\mathbf{1 C y}$ iodide salt; S: solvent, A: acetone

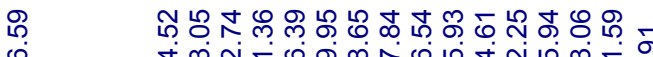
i $\quad \quad \quad$ 过

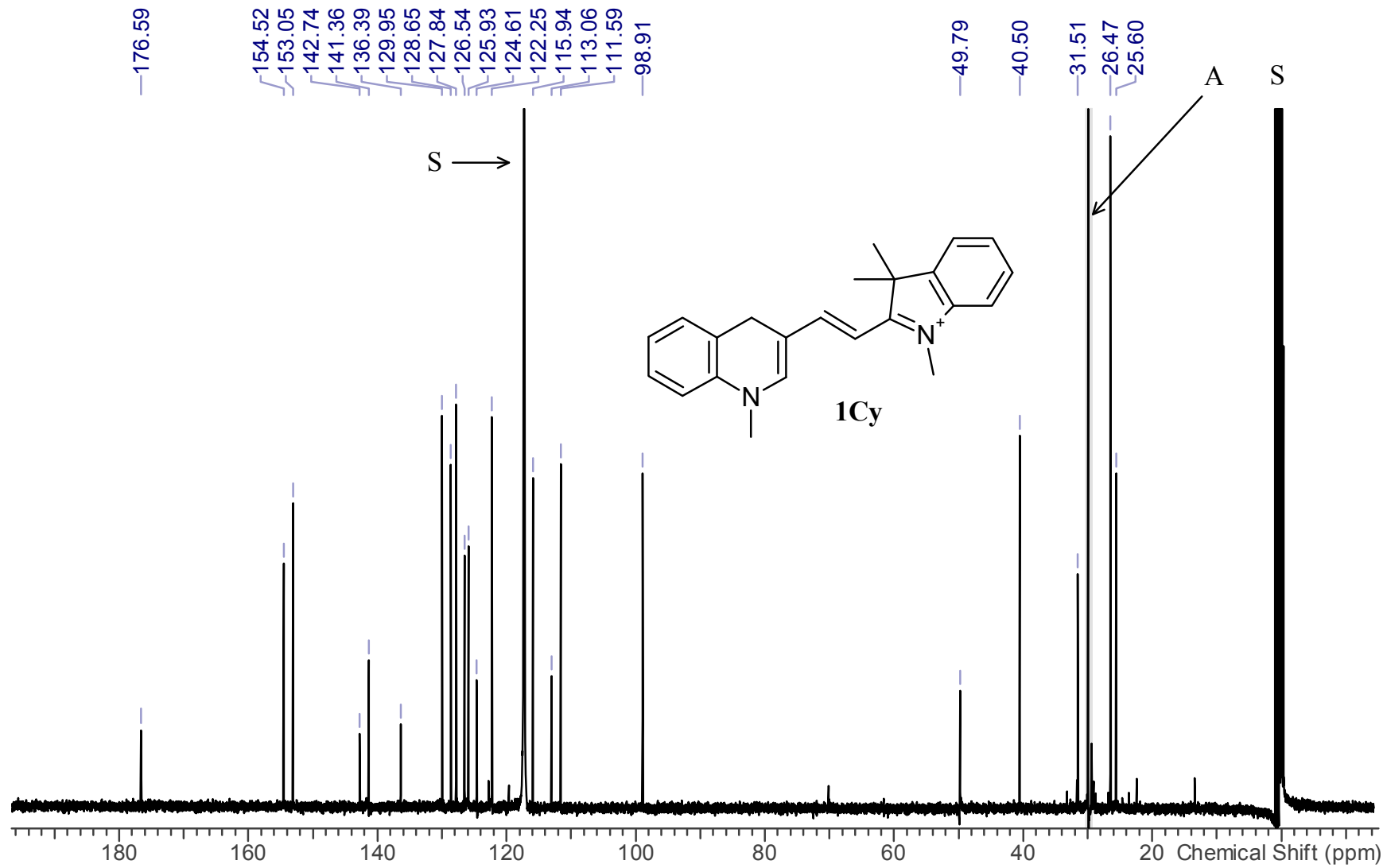


${ }^{1} \mathrm{H}$ NMR (DMSO- $\mathrm{d}_{6}, 400 \mathrm{MHz}$ ) for $\mathbf{2}$ iodide trifluoromethanesulfonate salt; S: solvent, W: water

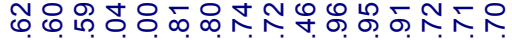

कं

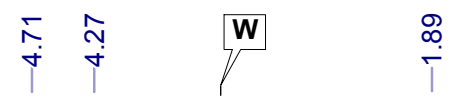<smiles>C[N+]1=C(C=Cc2cccc3c2ccc[n+]3C)C(C)(C)c2ccccc21</smiles>

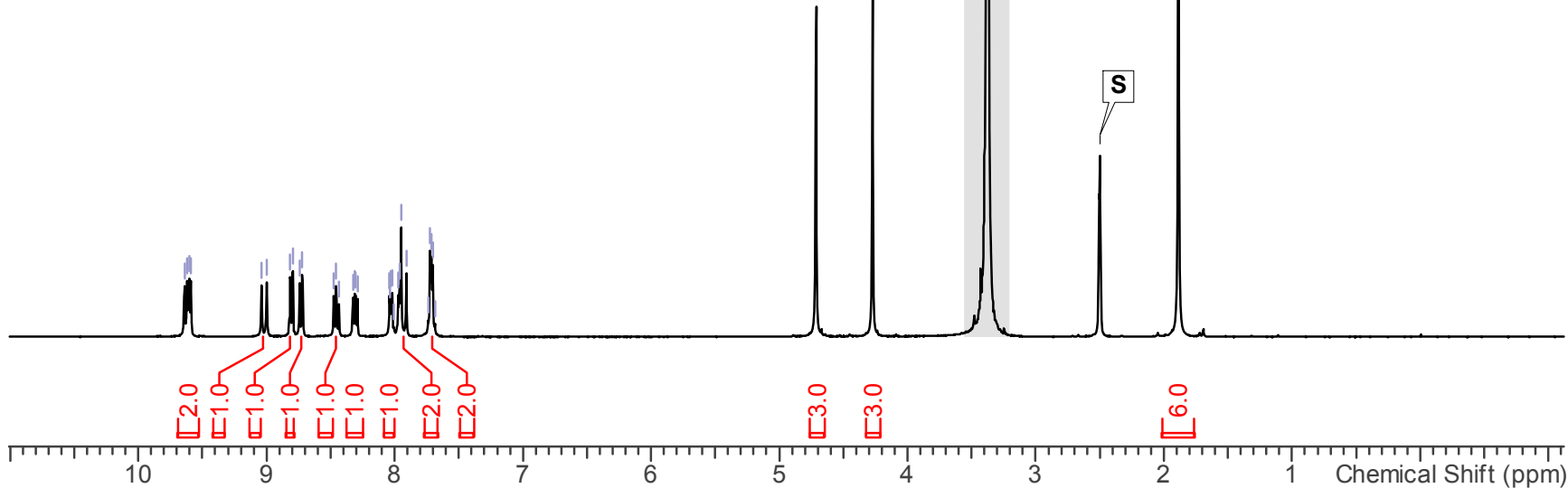

${ }^{13} \mathrm{C}$ NMR (DMSO-d $\mathrm{d}_{6}, 100 \mathrm{MHz}$ ) for $\mathbf{2}$ iodide trifluoromethanesulfonate salt; $\mathrm{S}$ : solvent

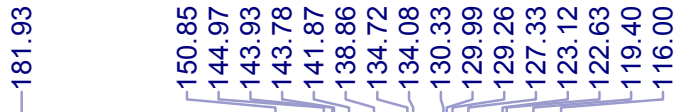

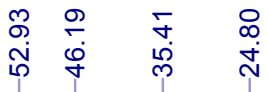<smiles>C[N+]1=C(/C=C/c2cccc3c2ccc[n+]3C)C(C)(C)c2ccccc21</smiles>

2

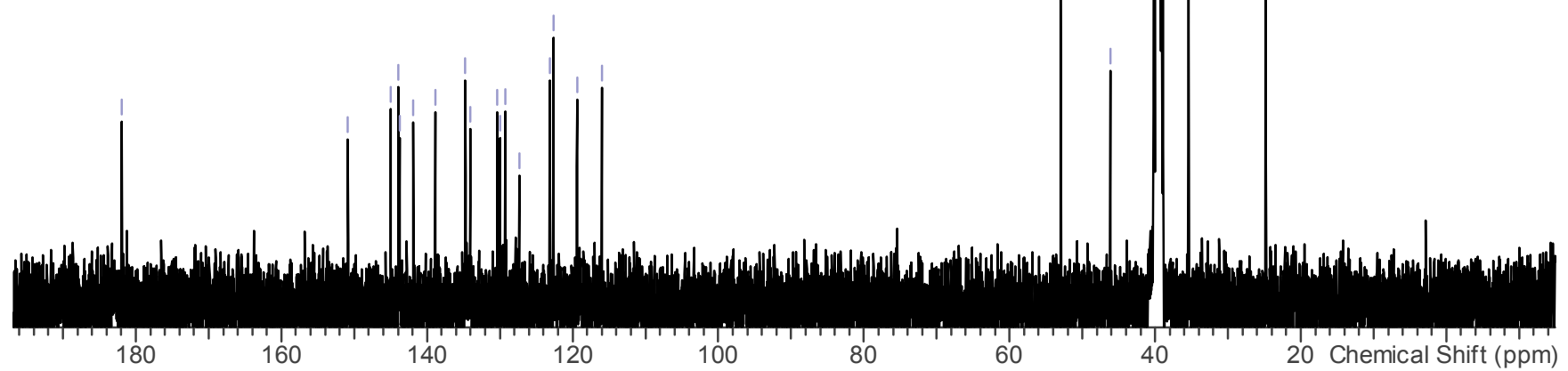


${ }^{1} \mathrm{H}$ NMR (DMSO-d 6 , $600 \mathrm{MHz}$ ) for 3 iodide trifluoromethanesulfonate salt; S: solvent, W: water

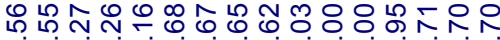

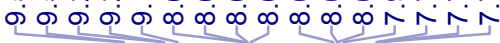
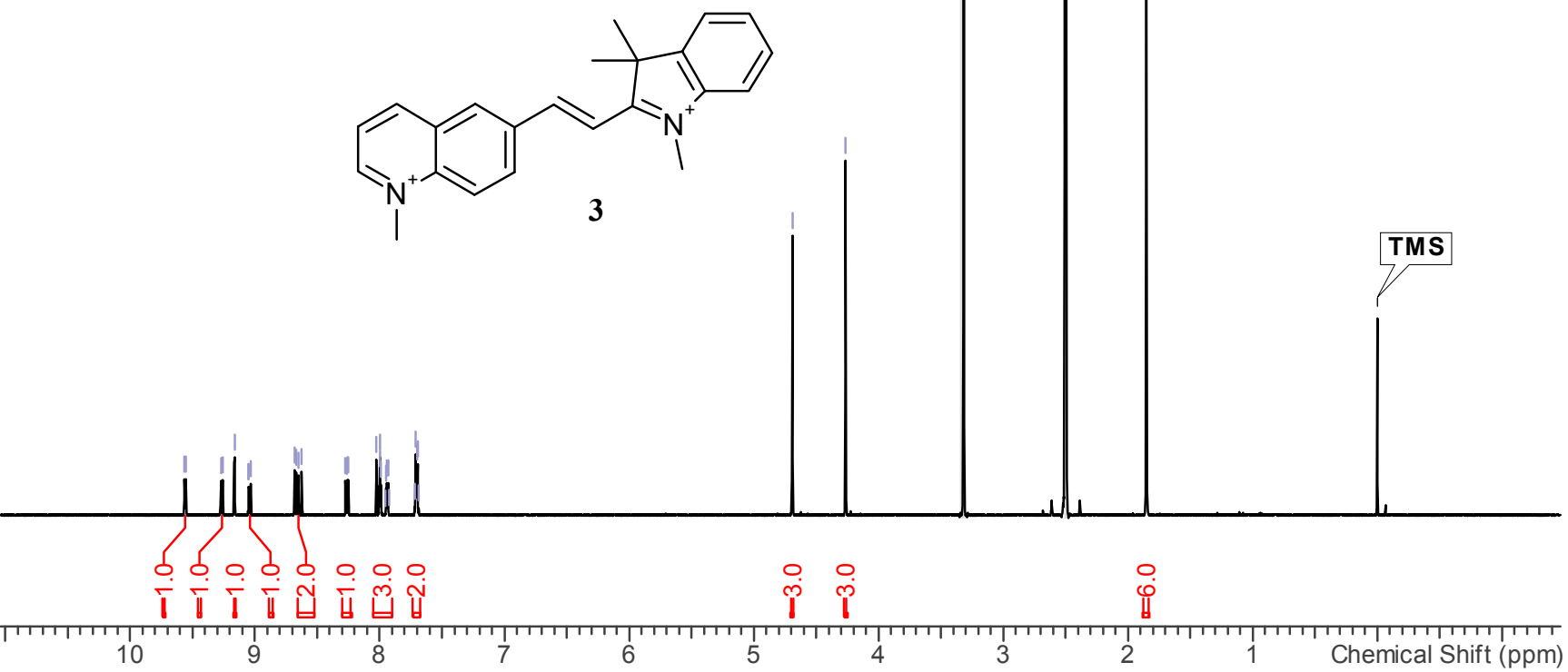

${ }^{13} \mathrm{C}$ NMR (DMSO-d $\mathrm{d}_{6}, 100 \mathrm{MHz}$ ) for 3 iodide trifluoromethanesulfonate salt; S: solvent

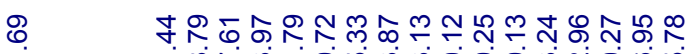

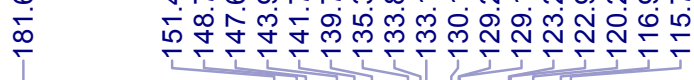<smiles></smiles>

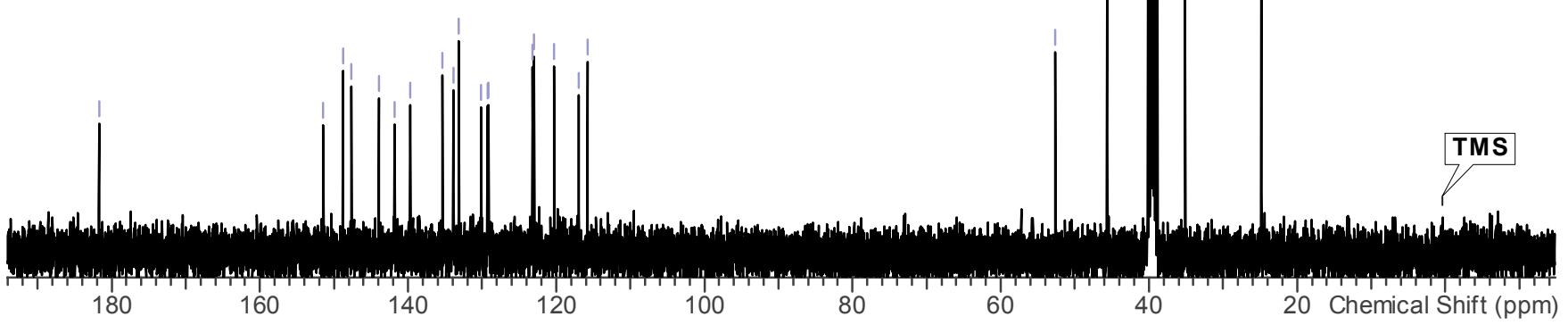


${ }^{1} \mathrm{H}$ NMR (DMSO- $\mathrm{d}_{6}, 400 \mathrm{MHz}$ ) for 4 iodide trifluoromethanesulfonate salt; S: solvent, W: water

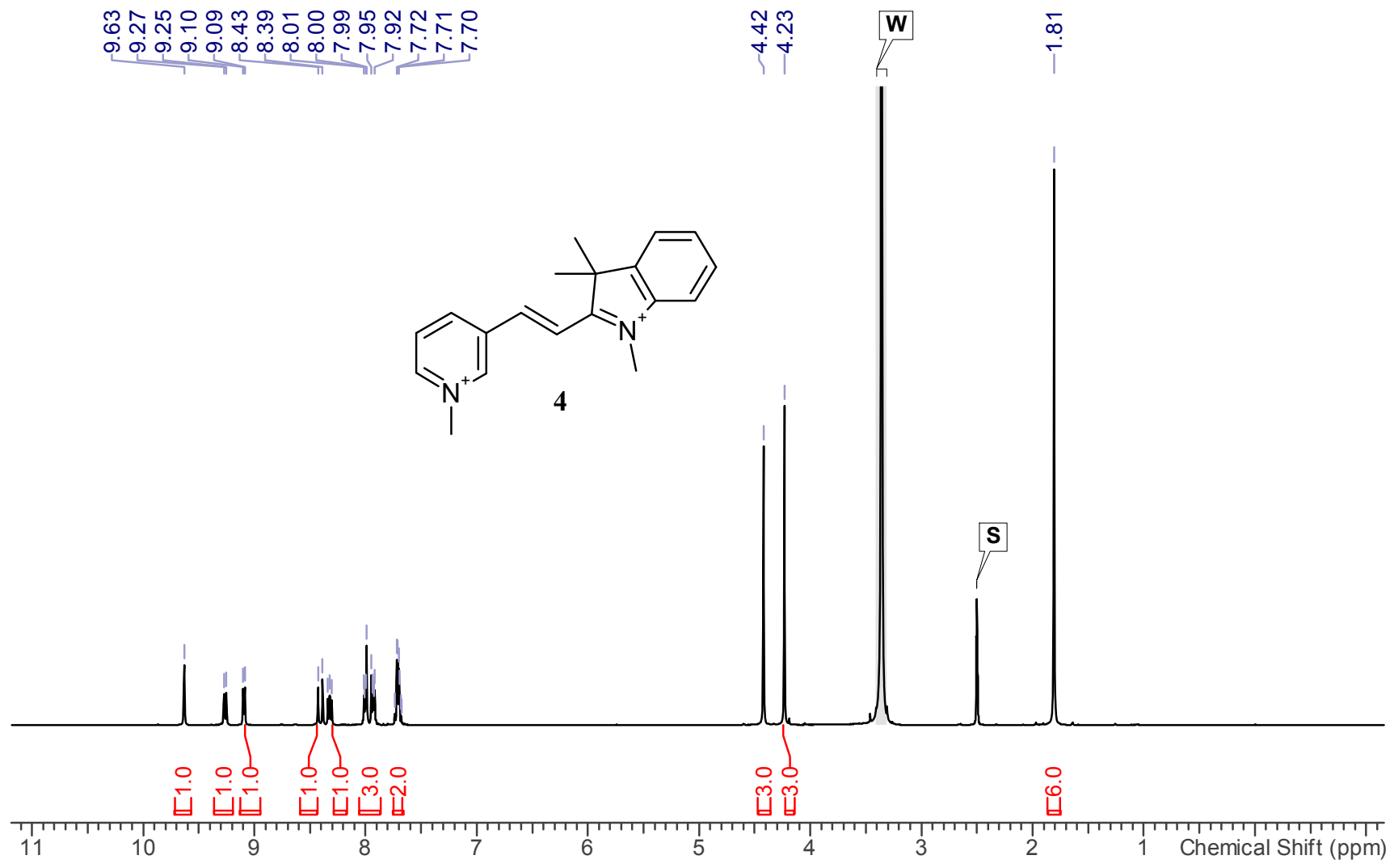

${ }^{13} \mathrm{C}$ NMR (DMSO-d $\mathrm{d}_{6}, 100 \mathrm{MHz}$ ) for 4 iodide trifluoromethanesulfonate salt; $\mathrm{S}$ : solvent

S

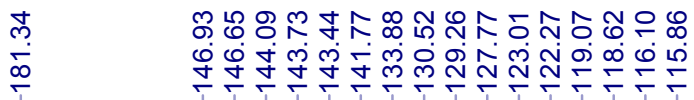

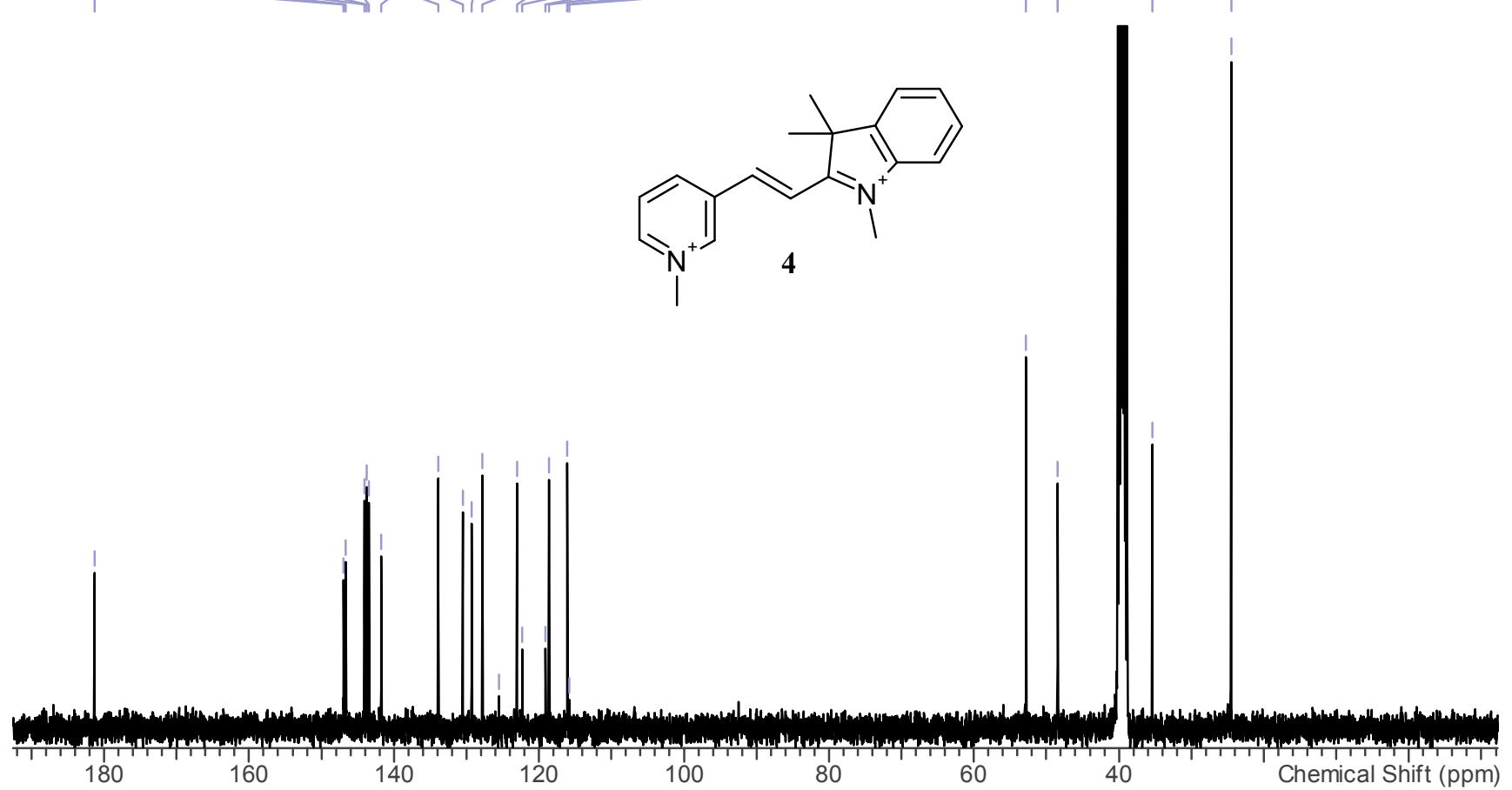

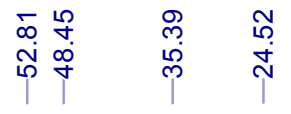


${ }^{1} \mathrm{H}$ NMR (DMSO- $\mathrm{d}_{6}, 400 \mathrm{MHz}$ ) for 5 iodide trifluoromethanesulfonate salt; S: solvent, W: water

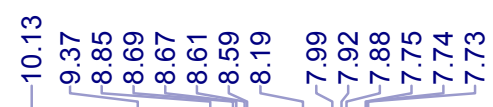

$\stackrel{\circ}{\circ} \stackrel{\infty}{\stackrel{\sim}{\sim}}$

w

$\stackrel{\infty}{\infty}$

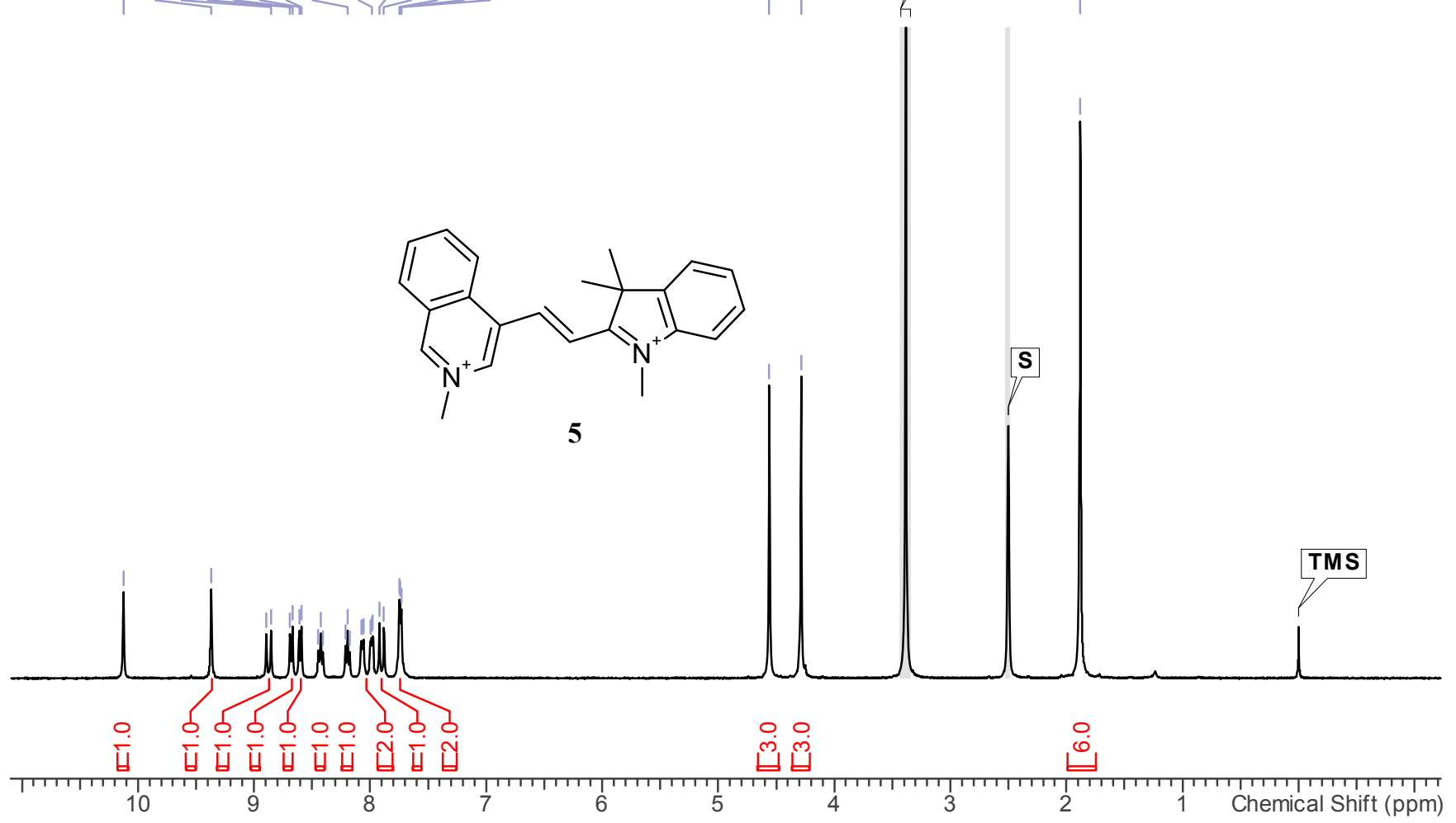

${ }^{13} \mathrm{C}$ NMR (DMSO- $\mathrm{d}_{6}, 100 \mathrm{MHz}$ ) for $\mathbf{5}$ iodide trifluoromethanesulfonate salt; S: solvent

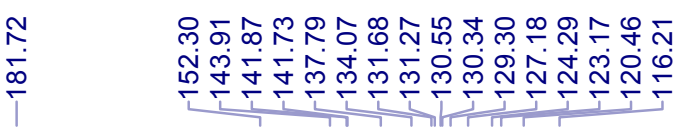

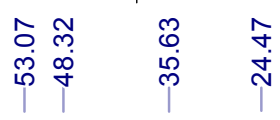

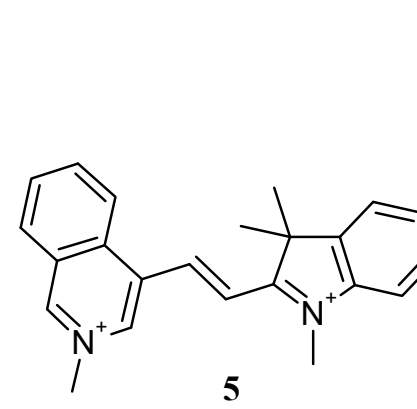

5

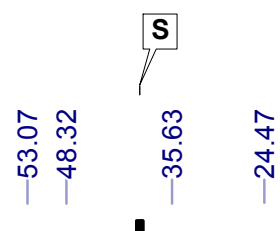

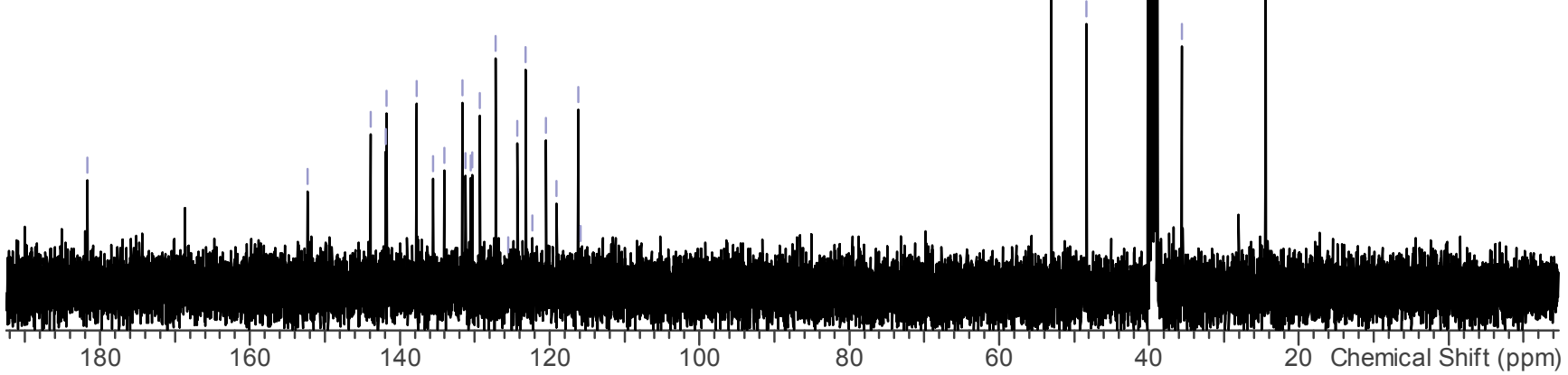


${ }^{1} \mathrm{H}$ NMR (MeOD-d $\mathrm{d}_{3}, 500 \mathrm{MHz}$ ) for 6 iodide trifluoromethanesulfonate salt; S: solvent, W: water

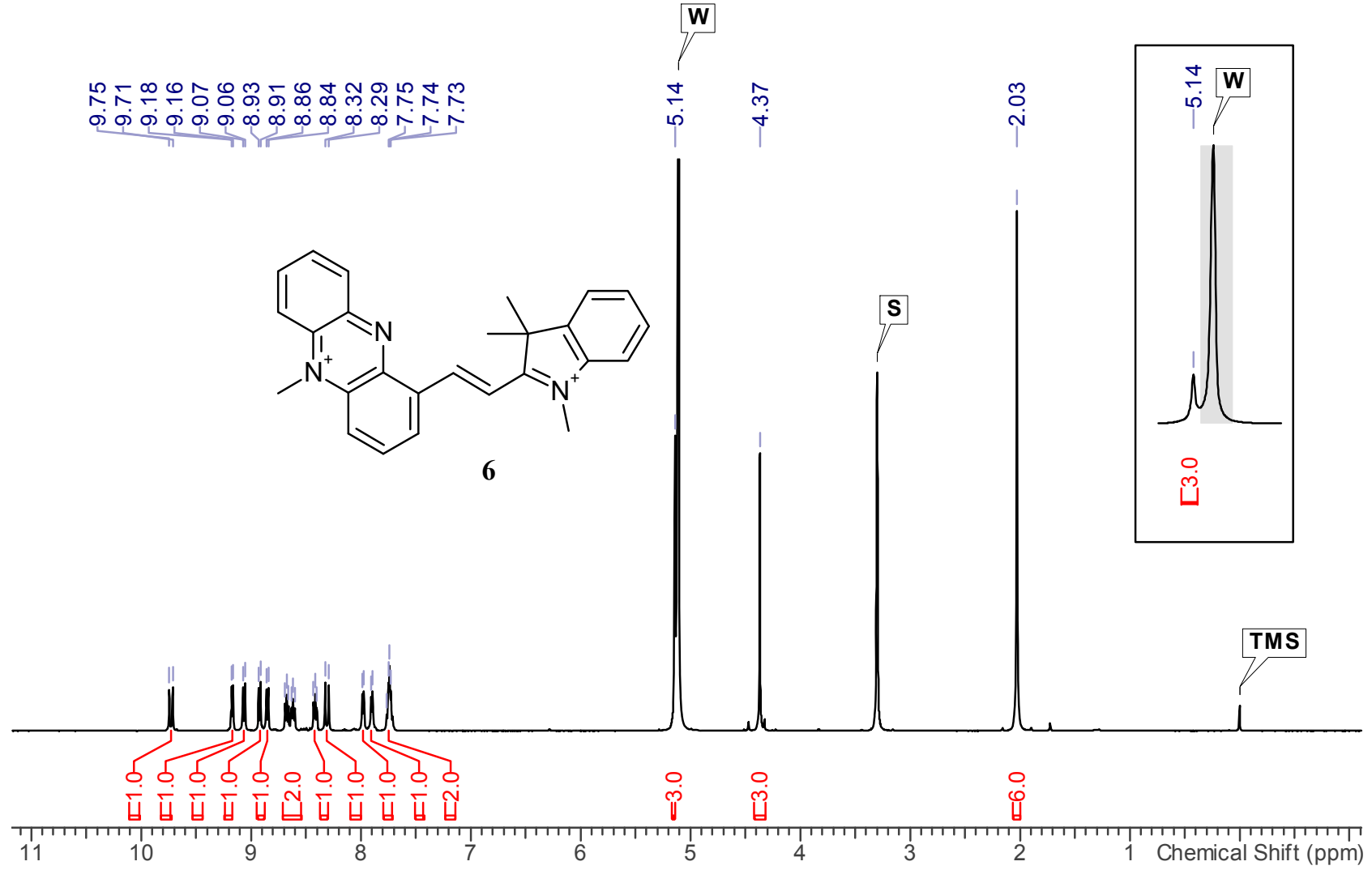

${ }^{13} \mathrm{C}$ NMR (MeOD- $\mathrm{d}_{3}, 125 \mathrm{MHz}$ ) for 6 iodide trifluoromethanesulfonate salt; $\mathrm{S}$ : solvent

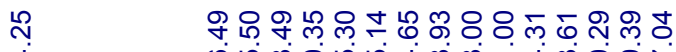

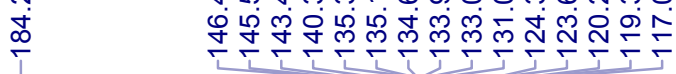

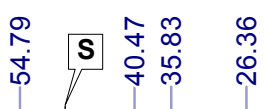

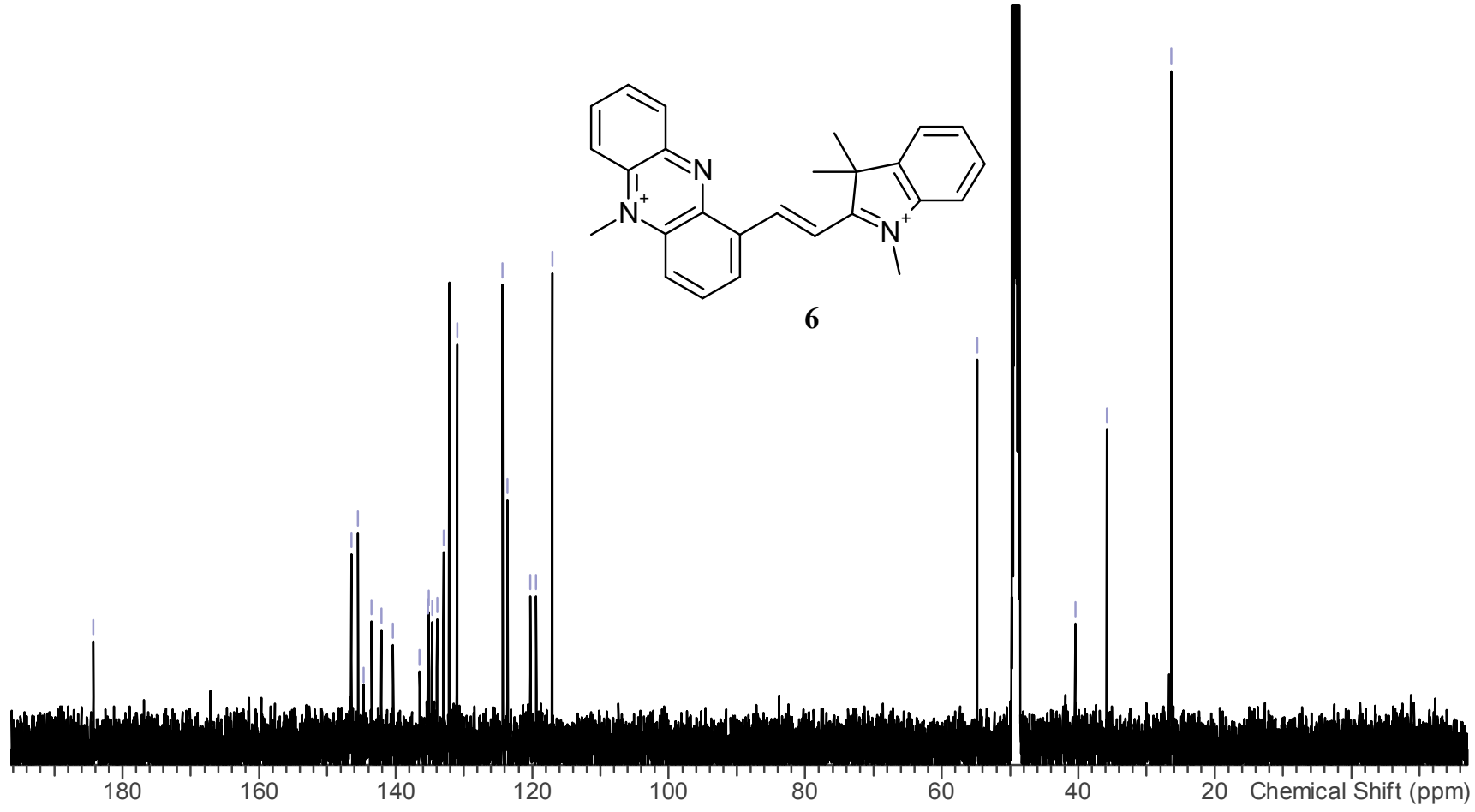


${ }^{1} \mathrm{H}$ NMR (DMSO-d 6 , $400 \mathrm{MHz}$ ) for 9 iodide salt; S: solvent, W: water

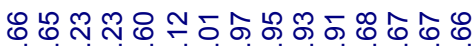

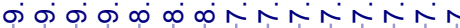

$\stackrel{\stackrel{n}{\sim}}{\sim}$

$\sqrt{\mathbf{\infty}} \stackrel{\infty}{\stackrel{\infty}{\leftarrow}}$<smiles>C[N+]1=C(/C=C/c2cnc3ccccc3c2)C(C)(C)c2ccccc21</smiles>

9
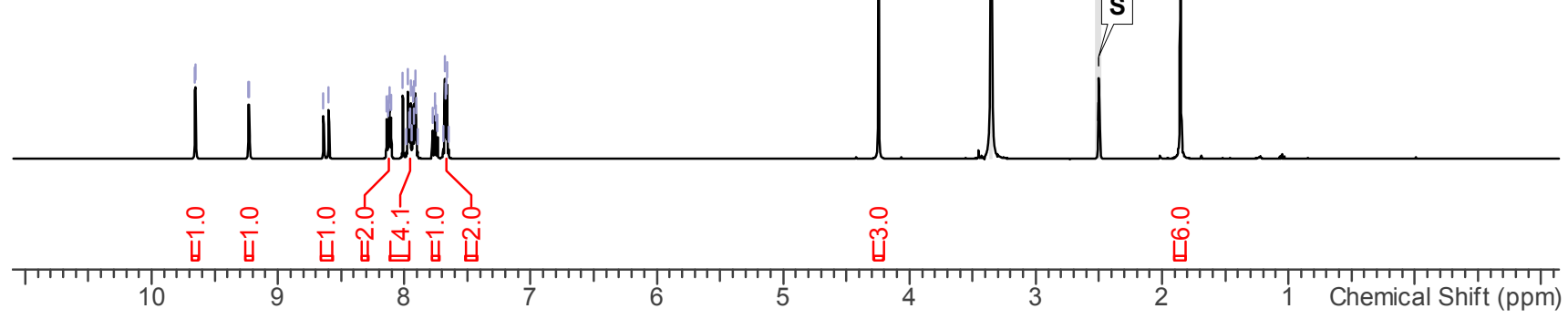

${ }^{13} \mathrm{C}$ NMR (DMSO-d $6,101 \mathrm{MHz}$ ) for 9 iodide salt; S: solvent
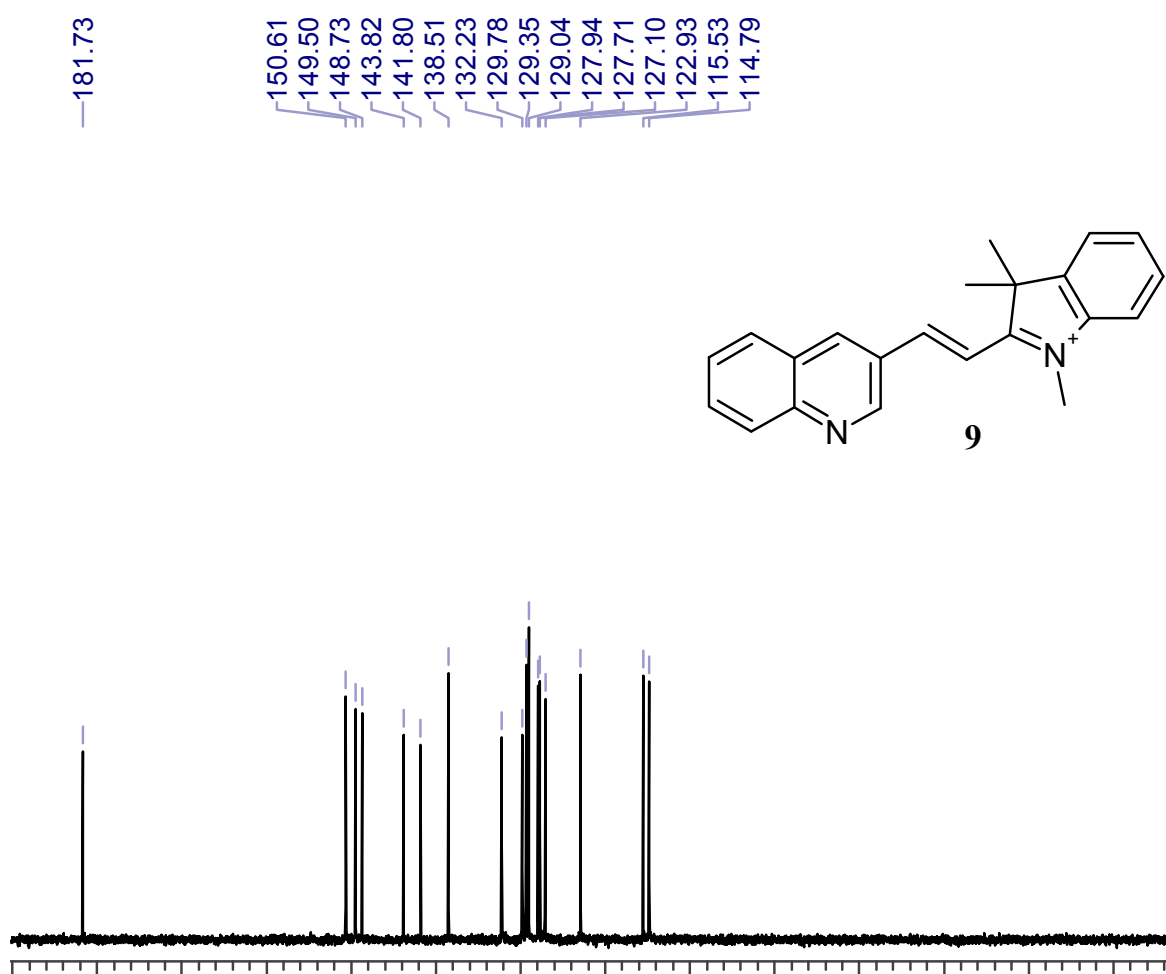
${ }^{1} \mathrm{H}$ NMR (DMSO-d $\mathrm{d}_{6}, 400 \mathrm{MHz}$ ) for 15 iodide salt; S: solvent, W: water, E: ethanol ก $8 \%$ ○ कांका का

$\stackrel{\text { N }}{ }$ W<smiles>C[N+]1=C(/C=C/c2cccc3ncccc23)C(C)(C)c2ccccc21</smiles>

15

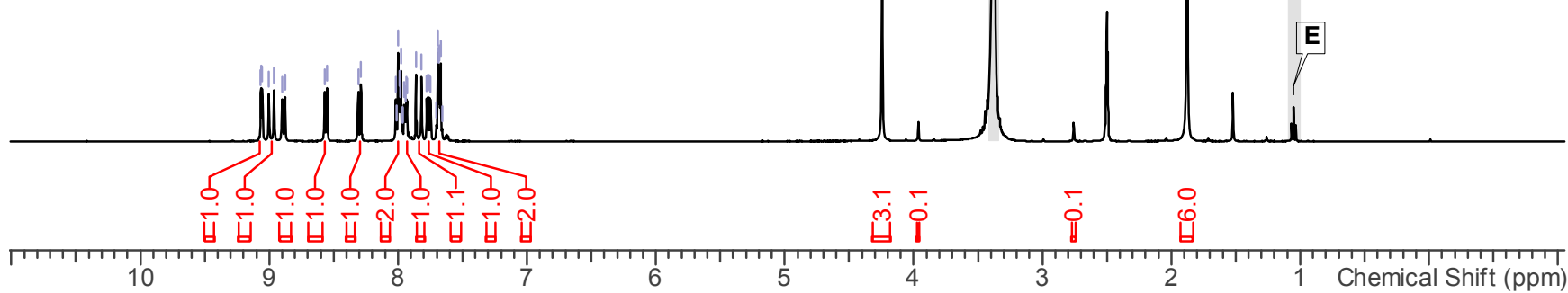

${ }^{13} \mathrm{C}$ NMR (DMSO- $\mathrm{d}_{6}, 101 \mathrm{MHz}$ ) for 15 iodide salt; S: solvent
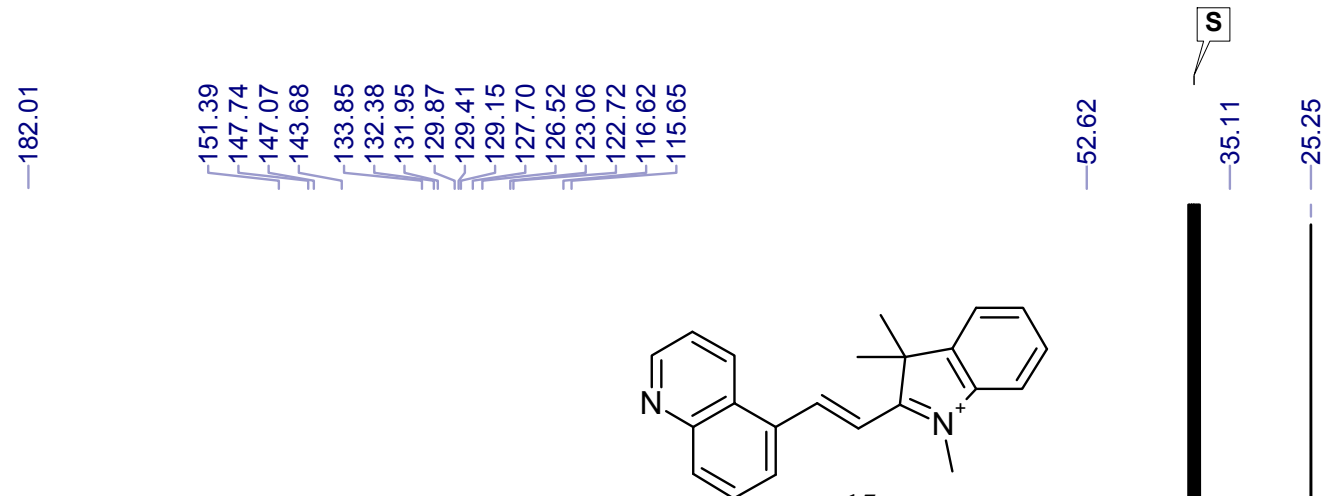

15

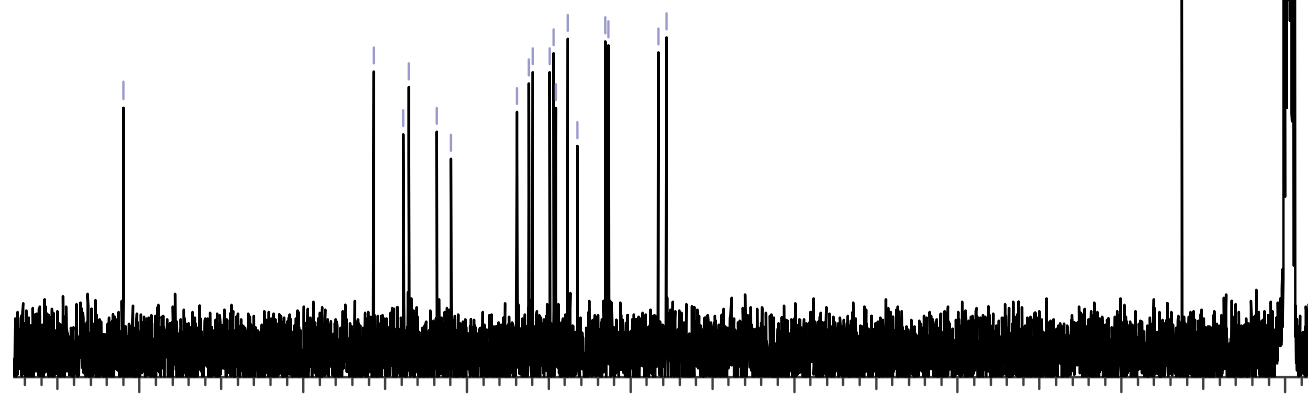


${ }^{1} \mathrm{H}$ NMR (DMSO- $\mathrm{d}_{6}, 600 \mathrm{MHz}$ ) for $\mathbf{1 6}$ iodide salt; $\mathrm{S}$ : solvent, W: water

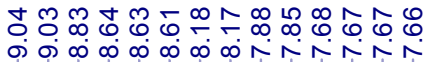<smiles>C[N+]1=C(/C=C/c2ccc3ncccc3c2)C(C)(C)c2ccccc21</smiles>

16

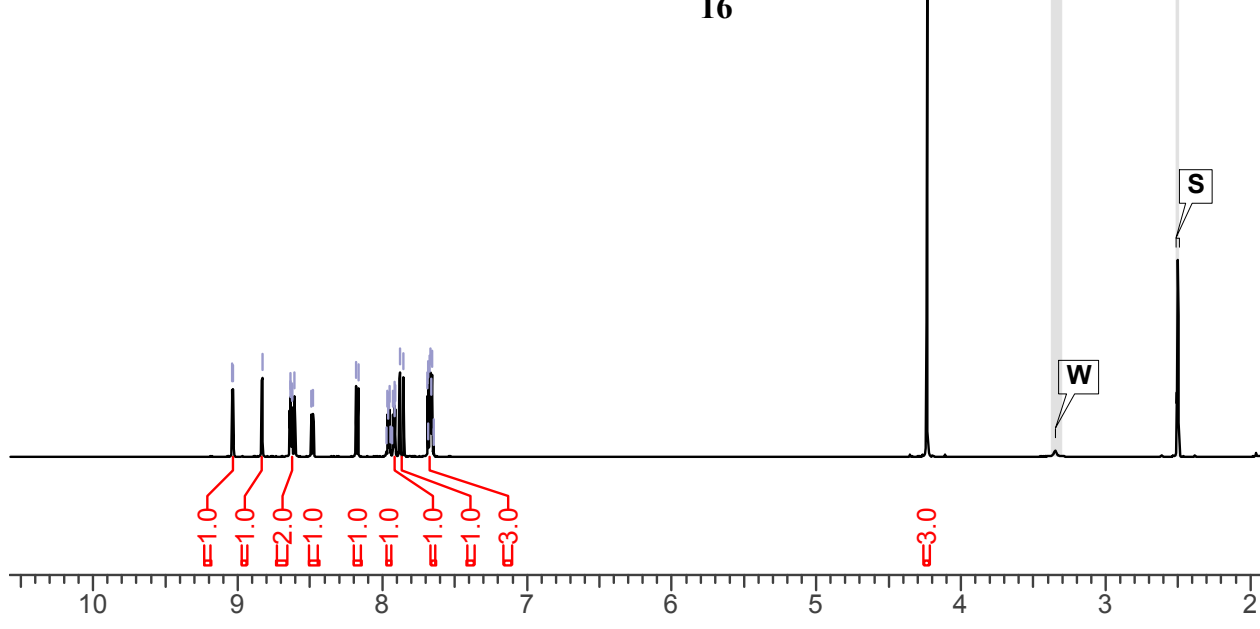

i.

${ }^{13} \mathrm{C}$ NMR (DMSO-d $\mathrm{d}_{6}, 150 \mathrm{MHz}$ ) for 16 iodide salt; S: solvent<smiles>C[N+]1=C(/C=C/c2ccc3ncccc3c2)C(C)(C)c2ccccc21</smiles>

16

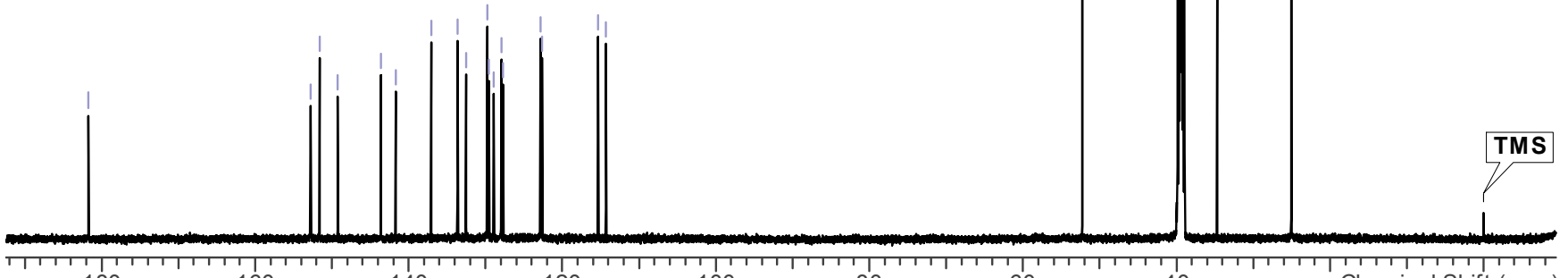


${ }^{1} \mathrm{H}$ NMR (DMSO-d $\mathrm{d}_{6}, 400 \mathrm{MHz}$ ) for $\mathbf{1 7}$ iodide salt; S: solvent, W: water

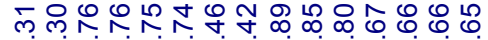

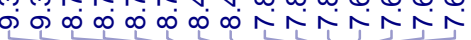<smiles>C[N+]1=C(/C=C/c2cccnc2)C(C)(C)c2ccccc21</smiles>

$\stackrel{9}{\leftarrow}$

W

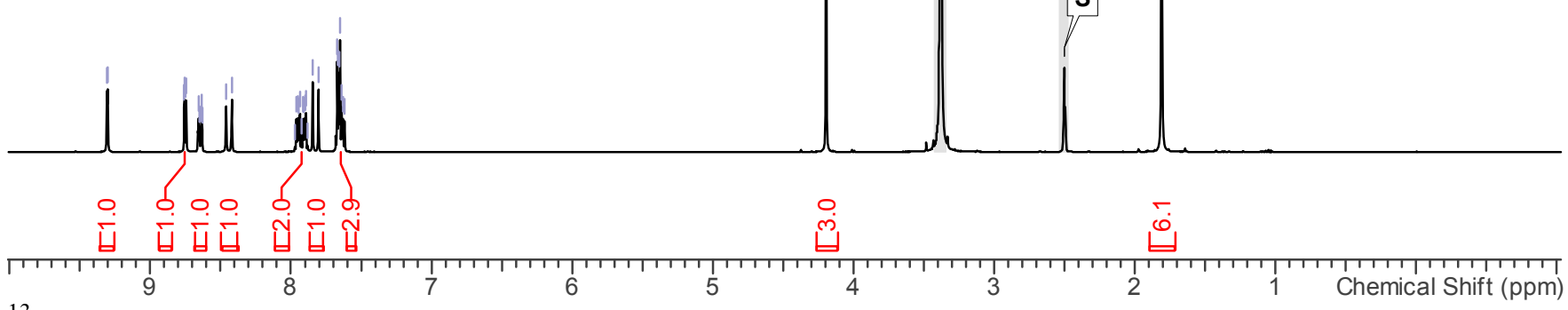

${ }^{13} \mathrm{C}$ NMR (DMSO-d $6,100 \mathrm{MHz}$ ) for 17 iodide salt; S: solvent

$\mathbf{S}$

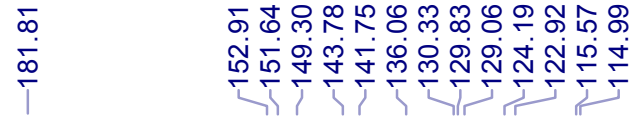<smiles>C[N+]1=C(/C=C/c2cccnc2)C(C)(C)c2ccccc21</smiles>

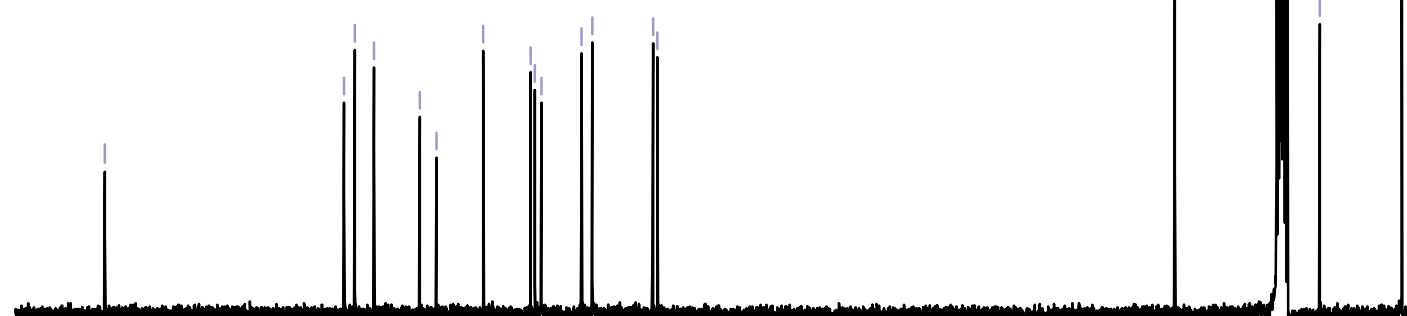


${ }^{1} \mathrm{H}$ NMR (DMSO- $\mathrm{d}_{6}, 400 \mathrm{MHz}$ ) for $\mathbf{1 8}$ iodide salt; S: solvent, W: water

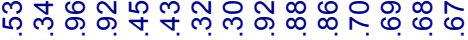
बं<smiles>C[N+]1=C(/C=C/c2cncc3ccccc23)C(C)(C)c2ccccc21</smiles>

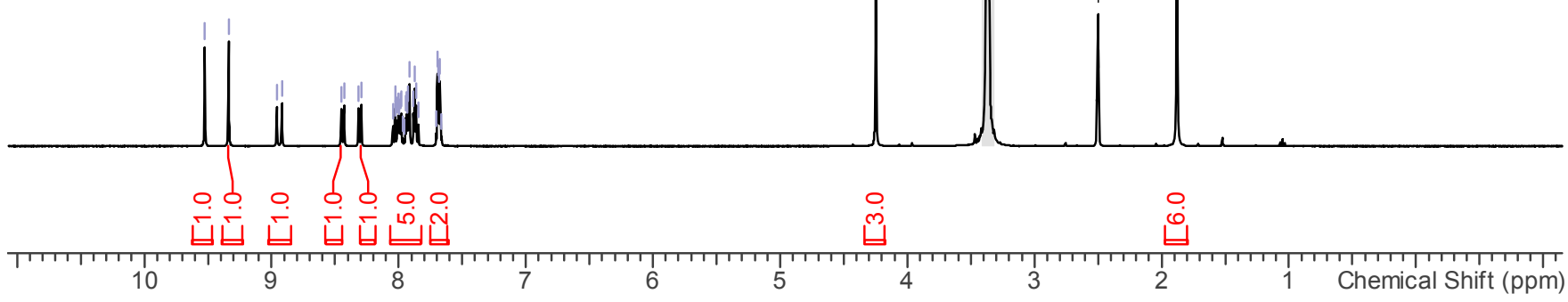

${ }^{13} \mathrm{C}$ NMR (DMSO-d $\mathrm{d}_{6}, 100 \mathrm{MHz}$ ) for 18 iodide salt; S: solvent

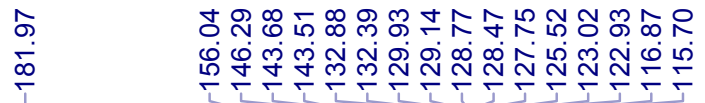<smiles>C[N+]1=C(/C=C/c2cncc3ccccc23)C(C)(C)c2ccccc21</smiles>

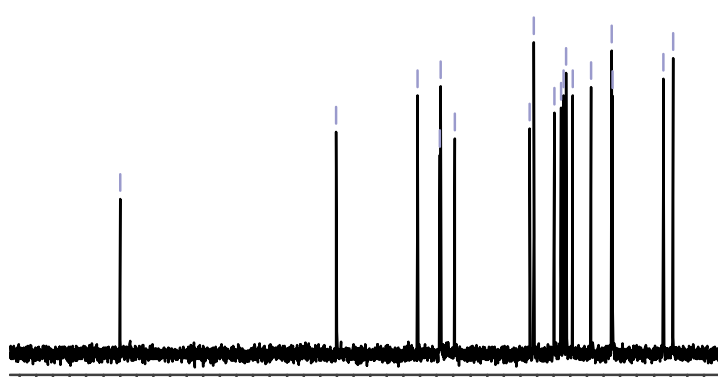


${ }^{1} \mathrm{H}$ NMR (DMSO- $\mathrm{d}_{6}, 600 \mathrm{MHz}$ ) for 19 iodide salt; $\mathrm{S}$ : solvent, W: water

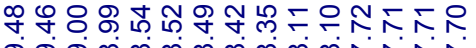

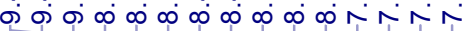

ঙ্ণ<smiles>C[N+]1=C(/C=C/c2cccc3nc4ccccc4nc23)C(C)(C)c2ccccc21</smiles>

19

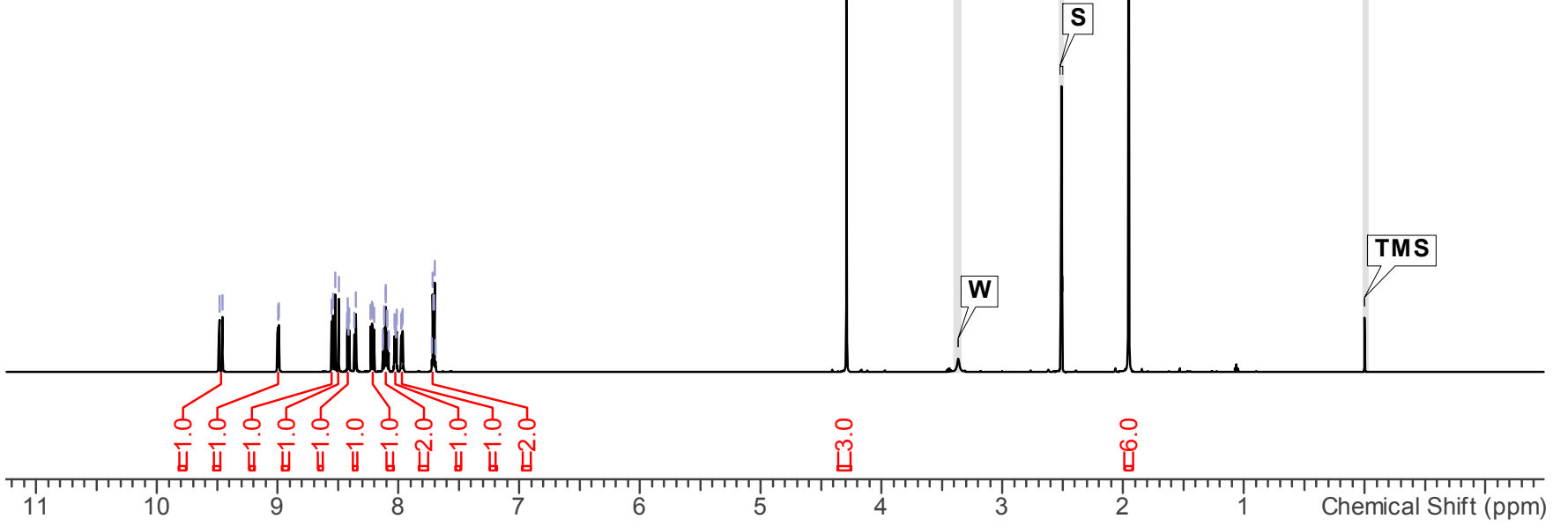

${ }^{13} \mathrm{C}$ NMR (DMSO- $\mathrm{d}_{6}, 150 \mathrm{MHz}$ ) for 19 iodide salt; S: solvent

S

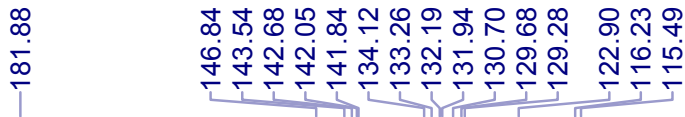

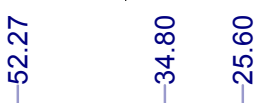<smiles>C[N+]1=C(/C=C/c2cccc3nc4ccccc4nc23)C(C)(C)c2ccccc21</smiles>

19

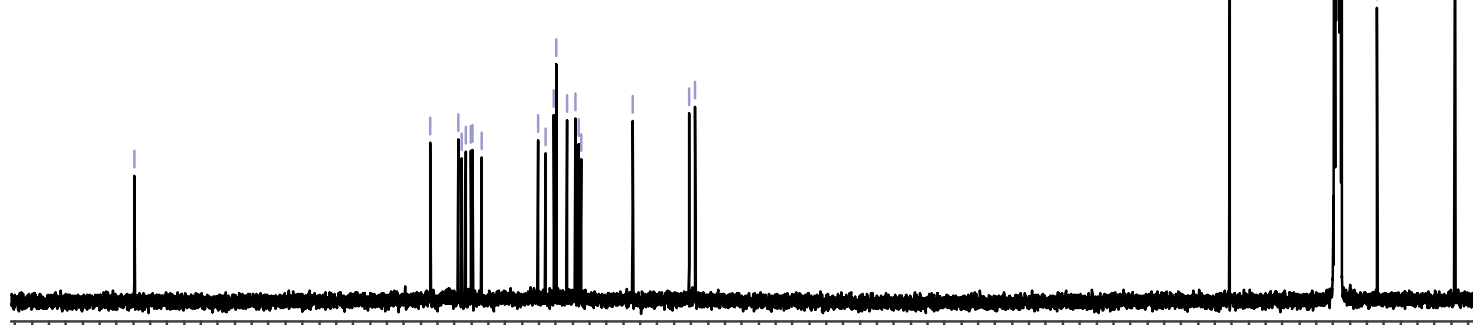




\section{References}

(1) Bluhm, L. H.; Li, T. Chromatographic purification of quaternary ammonium and pyridinium compounds on normal phase silica gel. Tetrahedron Lett. 1998, 39, 3623-3626.

(2) Gottlieb, H. E.; Kotlyar, V.; Nudelman, A. NMR Chemical Shifts of Common Laboratory Solvents as Trace Impurities. $J$. Org. Chem. 1997, 62, 7512-7515.

(3) Riché, E.; Carrié, A.; Andin, N.; Mabic, S. High-purity water and pH. Am. Lab. 2006, 38, 22. 